\title{
Understanding hope and its implications for consumer behavior: I hope, therefore I consume
}

Foundations and Trends in Marketing

\begin{abstract}
Building on prior work (MacInnis and de Mello (2005) 'The concept of hope and its relevance to product evaluation and choice'. Journal of Marketing 69(January), 1-14; de Mello and MacInnis (2005) 'Why and how consumers hope: Motivated reasoning and the marketplace'. Inside Consumption: Consumer Motives, Goals, and Desires, S. Ratneshwar and D. G. Mick (eds.). London/New York: Routledge, pp. 44-66), the authors argue that the concept of hope is highly relevant to consumer behavior and marketing, though its study has not yet appeared in these literatures. Complicating this study is that the definition of hope across literatures is inconsistent. The purpose of this conceptual article is to articulate the concept of hope and elucidate its relevance to consumer behavior. We do so in six sections. The first section explores the conceptual meaning of hope. A definition of hope and the constituent elements that underlie it is articulated. We compare this definition to ones provided elsewhere and differentiate hope from related terms like wishing, expectations, involvement, and faith. The second section focuses on what consumers hope for. The third section considers several important consumer relevant outcomes of hope, including biased processing and self-deception, risk taking behavior, product satisfaction, and life satisfaction and materialism. The fourth section addresses the extent to which marketers are purveyors of hope and what tactics they use to induce hope in consumers. The fifth section uses the conceptualization of hope to both discuss novel ways of measuring hope and their comparisons to existing hope measures. The final section addresses a set of interesting, yet unresolved questions about hope and consumer behavior.
\end{abstract}

MacInnis, Deborah J.^Chun, Hae Eun

Full Text: COPYRIGHT 2006 Now Publishers, Inc. http://www.nowpublishers.com 


\section{Introduction}

One notable human capacity is the ability to look to the future and aspire to achieve desired states. A majority of our behaviors such as applying cosmetics, reading self-help books, buying lottery tickets, and investing in the stock market betrays what we hope for, instead of what we are and where we are. The boundary of hope goes beyond what we hope for ourselves (e.g., hopes to make money, have fun, look more beautiful, find psychological happiness); we hope for our families (making life better for one's kids), hope for social groups (hoping one's team will win the game), and hope for our society (enhancing peace, social welfare).

Hoping that betterment of our lives will come true, we turn to the marketplace and strive to buy our dream. Indeed, the marketplace provides rich sources of hope and invites us to the endless pursuit of happiness. By selling hope as a marketable entity, the "beauty" industry, for instance, runs a profitable business. Cosmetic companies, pharmaceuticals, spas, beauty parlors, and magazines and books are only a few examples of this industry, which promote ways to better look, improve romantic relationships with a partner, and enhanced self-worth.

Hope also finds relevance within a broader realm of human behavior. Along with faith and charity, it is one of the three fundamental theological Christian virtues (Averill et al., 1990, Moltmann, 1980). Tiger (1979) surmises that religions arose from a biological need individuals have to feel hope.

Despite its relevance to human behavior in general and consumer behavior in particular, little has been written about the concept of hope. Some 40 years ago, Cohen (1958) observed, "Although life without hope is unthinkable, psychology without hope is not, judging by the conspicuous absence of any study of hope from the literature" (pg. 10). Little has changed in the status of the study of hope in the interim, as Lazarus (1999a) expounds, "With a modest number of exceptions ... there has been a great reluctance on the part of psychologists to address the concept of hope" (pg. 653). Furthermore, though some researchers recognize its importance, definitions in the psychology, sociology, philosophy, medical, and religion literatures often conceptualize hope in different ways. Nunn (1996) views hope as "a general tendency to construct and respond to the perceived future positively" (pg. 228). Snyder et al. (1996) define hope as a cognitive set comprising agency and pathways to reach goals. Pieper (1994) regards hope as an emotion that occurs when what one is expecting is good, signifying all that one longs for. Stotland (1969) equates hope with expectations and importance. Furthermore, a number of terms bear seeming relationship to hope, though they are not typically distinguished from hope: wishing, wanting, optimism, expectations, and faith. Thus, we are left wondering, "what is hope?" and "how is hope relevant to consumer behavior and marketing?"

The purpose of this conceptual paper is to shed light on the relevance and importance of hope to consumer behavior. We do so in six chapters. The first chapter explores the conceptual meaning of hope. A definition of hope and the constituent elements that underlie it is articulated. We compare this definition to ones provided elsewhere and differentiate hope from related terms like wishing, expectations, and faith. The second chapter focuses on what consumers hope for. The third chapter considers several (though not all) important consumer relevant outcomes of hope, including biased processing and self-deception, risk taking behavior, product satisfaction, and life satisfaction and materialism. The fourth chapter addresses the extent to which marketers are purveyors of hope and what tactics they use to induce hope in consumers. The fifth chapter uses the conceptualization of hope to both discuss novel ways of measuring hope and their comparisons to existing hope measures. The final chapter addresses a set of interesting, yet unresolved questions about hope and consumer behavior. 


\section{What is hope?}

\subsection{Definition of Hope}

Hope is a common word in everyday language. Research by Shimano. (1984) finds that in everyday conversations, hope is one of the most frequently named emotions. Consistent with its prevalent usage in everyday vernacular, a recent search on the popular sites Amazon.com revealed 449,735 books, 1,983 CDs, and 889 personal care products with hope in the name. In a consumer context, consumers hope, among other things, to look cool, quit smoking, lose weight, have a beautiful home, win the lottery, relax, look younger, and find enlightenment. A consideration of consumer hope and the contexts in which it occurs reveals several fundamental factors about the concept of hope (see MacInnis and de Mello, 2005, de Mello and MacInnis, 2005).

\subsubsection{Goal Congruence}

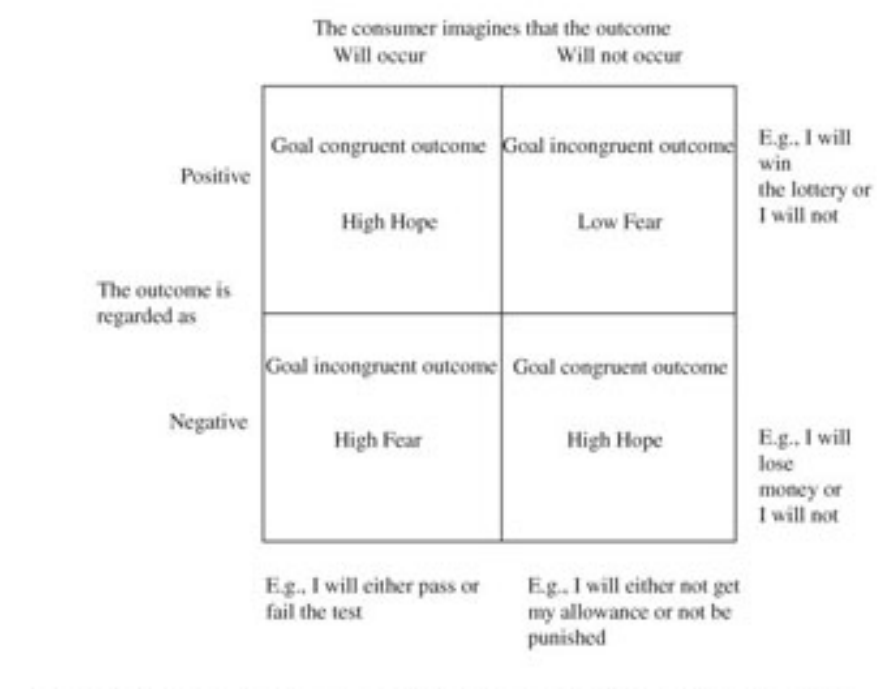

Fig. 1.1 Goal coagreent and incongruent outcomes and their relationship to bope.

Hope is felt in relation to outcomes appraised as favorable or goal congruent (Lazarus, 1991, Smith et al., 1993, Roseman, 1991). Goal congruence reflects the extent to which the environment is consistent with one's goals. In a benign environment, "goal congruent" means that a favorable outcome could occur. In an aversive or threatening environment, "goal congruent" means that a negative outcome could be avoided or solved (see Figure 1.1). Individuals hope they do win the lottery and hope they do not have cancer, as both outcomes are perceived as goal congruent. Hope thus applies equally to consumers with a promotion or prevention focus (e.g., Pham and Higgins, 2005, Higgins, 1997, de Mello and MacInnis, 2005). Under promotion focus, hope means that a favorable outcome can be achieved, whereas under a prevention focus, hope implies that a bad outcome can be avoided. Other outcomes are goal irrelevant, as their occurrence has no implications for goals. A non-sports fan feels no hope that a particular team wins the game because her status as a non-fan makes the outcome irrelevant to her. Still other outcomes are goal incongruent. In a benign environment, "goal incongruent" means that a positive outcome will not occur. In an aversive environment, "goal incongruent" means that a negative outcome will occur (see Figure 1.1). For example, one would not hope that one would fail to win the lottery, or that one's house would burn down in a fire, as these outcomes are likely perceived as goal incongruent.

[FIGURE 1.1 OMITTED]

\subsubsection{Yearning}


Goal congruent outcomes exist in a goal hierarchy (Austin and Vancouver, 1996), with higher order goals associated with greater yearning than lower order goals. Hence, Lazarus (1991) points out an important component of hope--one experiences greater hope for outcomes that one yearns for. Yearning is defined as the degree of longing for a goal congruent outcome. This idea is reflected in Table 1.1, as hope is embedded within outcomes regarded as goal congruent and linked with outcomes associated with greater as opposed to weaker levels of yearning. A depressed consumer may have intense yearning to alleviate her depression, yet only mild yearning to look sexy in a new dress. Consistent with the notion that yearning is part of hope, Averill et al. (1990) found that college students reported terminating hope when yearning for the goal congruent outcome ceased. Since the concept of yearning is relatively new to the consumer behavior literature, we briefly discuss factors that affect yearning below.

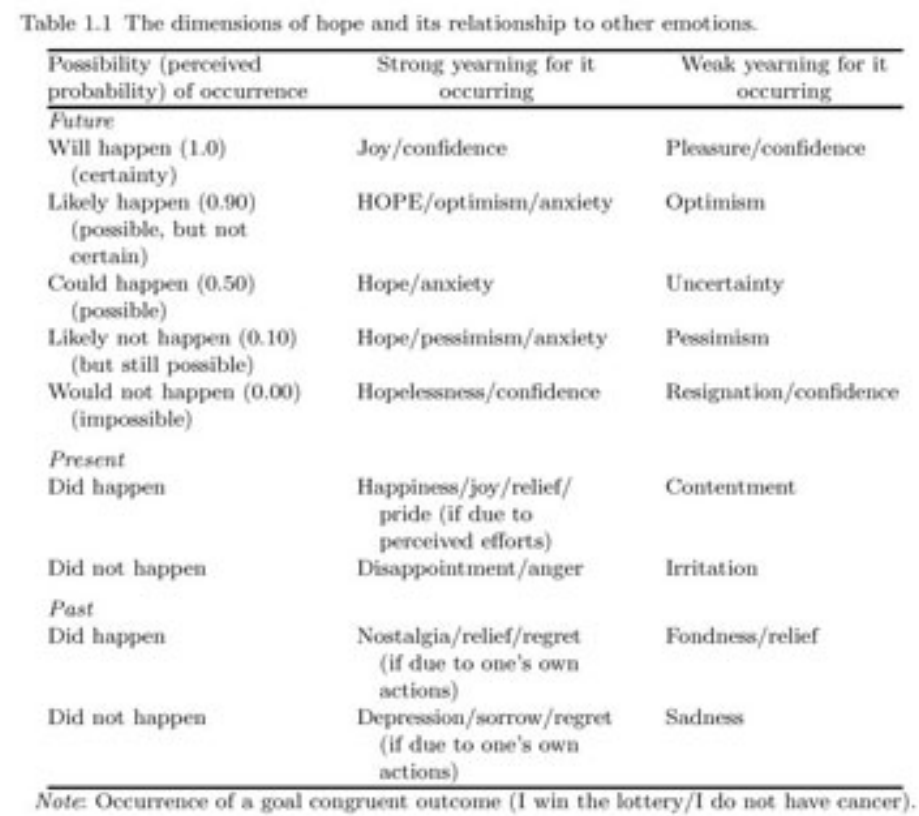

A fundamental factor associated with yearning is desire; we are more likely to long or yearn for outcomes that we desire. Belk et al. (1997) write that consumer desire is "an intensely passionate positive emotional experience steeped in fantasies and dreams rather than an experience involving reasoned judgments" (pg. 24). Desires for great wealth were, for example, a mighty pull in stimulating hopes for gold in the California Gold Rush (Hamilton, 1978). Sexual desire is a strong stimulator of yearning for consumers who prowl bars at night in the hope of finding a partner.

Yearning is also related to the importance of an outcome. While a consumer may not have a desire to join the military, doing so may be important to his self-concept and hence stimulate his yearning to enlist. As evidence of the relationship of importance to hope, objects or events associated with hope were all described as highly important (Averill et al., 1990, Bruininks and Malle, 2005). Hope was not viewed as an appropriate emotion when the outcome was trivial or unimportant. Stotland (1969) also gives importance a prominent role in hope. Thus, we expect that consumers experience greater yearning and hence more intense hope for outcomes appraised as important (e.g., I hope this drug cures my cancer) than less important (e.g., I hope this relaxation tape relaxes me).

Finally, yearning is related to deficiencies. Lazarus (1999a; see also Rycroft, 1979) opines, "A fundamental condition of yearning and hope is that our current life circumstance is unsatisfactory--that is, it involves deprivation" (pg. 653). Thus a gambler down to his last few dollars will experience more yearning and greater hope for winning the lottery than the person who has a secure financial status. Though little empirical research has focused on deficiency as an important component of yearning and hope, Hamilton (1978) indicates that perceived deficiencies in economic conditions were commonly viewed as sources stimulating hopes for gold in the California Gold Rush. Perceived deficiency also appears to motivate lottery 
consumption and hope for a big win. Clotfelter and Cook (1989) found that participation in the lottery is greatest among those consumers with the most limited economic means.

\subsubsection{Future Orientation}

Hope is future oriented as it focuses on actions and outcomes that have yet to be realized (Lazarus, 1991, Smith et al., 1993). When we say that we hope to quit smoking, win the championship, or find enlightenment we are suggesting that the act of quitting, winning, or discovering meaning has not yet occurred. Outcomes that are being realized in the present are linked with different feelings like happiness, joy and elation, and surprise. In other words, emotions like hope can be conceptualized along a time continuum, ranging from past, present, and future (see Table 1.1). Those that have occurred in the past are linked with feelings like nostalgia and sadness (see Table 1.1). Hope (like fear and anxiety) falls into the range of emotions to anticipated outcomes as opposed to concurrent or experienced outcomes (Bagozzi et al., 2000). Consistent with the notion that future orientation is an important part of hope, Averill et al. (1990) found that college students reported terminating hope when the time during which the hoped for outcome should have occurred had passed.

\subsubsection{Possibility/Uncertainty}

Being future oriented, hope involves outcomes whose actual occurrence is viewed as possible, but uncertain (Lazarus, 1991, Smith et al., 1993, Roseman, 1991, Frijda et al., 1989). Uncertainty is a core element, as hope is unlikely to occur when one is certain that the goal congruent outcome will arise, or certain that it will not (i.e., the perceived probability of the goal congruent outcome is 1.0 or 0) (Pieper, 1994). The relationship between hope and uncertainty is thus nonlinear. In fact, hope can be experienced even when the perceived probability of the goal congruent outcome is relatively low or relatively high. For example, one can hope to win the lottery, knowing full well that the probability of doing so is slim. Likewise, a well-prepared student can hope to do well on a test even though her level preparation suggests that probability of doing so is relatively high. This idea gybes with Averill et al. (1990) whose respondents reported terminating hope when they realized that what they hoped for was completely under their control and hence certain, or when they decided that there was no chance of achieving it. These notions are reflected in Table 1.1.

\subsubsection{Hope as an Emotion}

There has been considerable controversy over whether hope is or is not an emotion. On the one hand, Solomon (2000) notes that Thomas Aquinas viewed hope as a virtue and more akin to reason than emotion. Hope does not appear on standard emotion typologies of arousal, dominance, and valence (Russell, 1980). Nor does it appear in Plutchik's (1980) General Psychoevolutionary theory of emotions or Watson and Tellegen's (1985) circumplex model of emotion. On the other hand, hope was regarded as a fundamental emotion during medieval times (Averill et al., 1990). In his seminal book The Principle of Hope, philosopher Ernst Bloch (1986) suggests hope is an emotion that can be learned. Furthermore, hope has similarities to emotions like love and anger: All are perceived to be difficult to control, all can affect the way one thinks, all can lead an individual to act in uncharacteristic and non-rational ways, all are common experiences, and all can motivate behavior (Averill et al., 1990). Bruininks and Malle (2005) indeed showed that hope was described by most people as an emotion.

Some (e.g., Averill, 1991, Rycroft, 1979, Lazarus, 1999a) suggest that hope does not appear on standard emotion scales because the emotion theories from which these scales are derived emphasize basic emotions like fear, anger, and love, which have a strong biological and physiological focus as opposed to intellectual emotions like hope (MacInnis and de Mello, 2005). Hope may be a higher order emotion as assessment of possibilities and future orientations, which may not be possible in non-humans, is required in order for hope to be evoked, and hence not evident in an evolutionary theory of emotions.

Only recently, hope has emerged as a bona file emotion as appraisal theory developed as a theoretical 
approach to emotions (e.g., Arnold, 1960, Frijda, 2000, Lazarus, 1991, Smith et al., 1993, Shaver et al., 1987, Smith and Ellsworth, 1985, Roseman, 1991). According to appraisal theory, emotions are caused by appraisals or perceptions of a given situation. Hence emotions have cognitions like assessments of certainty, future orientation, and goal congruity as their antecedents.

The notion that hope is an emotion fits recent appraisal theories of emotion quite well--it has a primary appraisal component of goal relevance and goal congruence. (1) It has a secondary appraisal of being uncertain. It has an action tendency of yearning and approach moving toward the goal congruent outcome (Lazarus, 1991).

Table 1.1 shows that hope is one of a number of emotions experienced in situations described by degrees of yearning for a goal congruent outcome and uncertainty regarding the future. Different levels of these dimensions are associated with different emotions, and still different emotions are associated with present or past (vs. future) outcomes. (2) Thus, Table 1.1 logically links hope with other emotions.

Based on the core constituent elements, we define hope as a positive emotion that varies as a function of the degree of yearning for a goal congruent, future oriented outcome appraised as uncertain, yet possible (de Mello and MacInnis, 2005, MacInnis and de Mello, 2005). Since yearning is embedded within goal congruence and uncertainty is embedded within future orientation (see Table 1.1), it is possible to define hope more parsimoniously as a positive emotion that varies as a function of the degree of yearning for an uncertain, yet possible outcome.

\subsection{How is Hope Different from Goals?}

The fact that hope relates to future oriented outcomes regarded as goal congruent puts the study of hope within the literature on goals and goal attainment (see Bagozzi and Dholakia, 1999, Huffman et al., 2000). While hope can be viewed within the domain of the goal literature, it complements this literature in two ways: (1) it focuses not on goals themselves, but on the outcomes presumed to result from goal achievement and (2) it adds an affective element to the study of goals by focusing on an emotion that arises from goal formulation and pursuit (de Mello and MacInnis, 2005; see also Bagozzi et al., 2000). Lazarus (1999a) indicates that emotions are not the same as goals, but rather arise from the presumed fate of goals. Hope, he argues, is and should be considered an emotion, as it is a response to goal outcomes.

\subsection{Comparison to Definitions of Hope in the Literature}

The myriad definitions of hope in diverse literatures are shown in Table 1.2. As shown there, definitions differ both from each other and the proposed definition in several ways. Several definitions regard hope as an emotion while others regard it as a cognition. Our definition gybes with Obayuwana et al. (1982), Haase et al. (1992), and Pieper (1994) who view hope as an emotion. As Korner (1970) writes, hope is differentiated from expecting or anticipating by its 'intense affective component" (pg. 134). He adds, 'Hope to the individual is an emotional experience, something that he can feel and sometimes think and talk about" (pg. 137).

Second, we view hope as an emotion evoked at a point in time and driven by historical and situational context. This view contrasts with Snyder et al. (1991; see also Nunn, 1996) who sometimes characterize hopes as an individual difference variable--identifying people described as high vs. low hope either dispositionally or within a given life domain. Rather than as an individual difference variable, we view hope as an emotion that describes the psychological state of an individual at a point in time.

Third, our definition is consistent with Obayuwana et al. (1992), Haase et al. (1992), and Rycroft (1979) by focusing on futures that are uncertain, yet possible. It contrasts with Pieper (1994), Stotland (1969), Staats 
(1989), and Snyder et al. (1996) who define hope in terms of expectations. Expectations suggest a level of perceived probability of a future event. However, uncertainty suggests that the perceived probability of an event is unknown (Oliver and Winer, 1987).

Finally, our definition views yearning and the components that comprise it as central to hope. Hence, our definition of hope maps Pieper (1994) who refers to the longing elements of hope. Our conceptualization of yearning as it relates to hope is also more inclusive than several other definitions. Though it bears similarity to Obayuwana et al. (1982) and Haase et al. (1992) by focusing on desire, it incorporates dimensions of yearning beyond desire. It also includes importance like Stotland (1969) but focuses on dimensions that affect yearning beyond importance. Rycroft (1979) alludes to the other two antecedents of yearning-deficiency and desire. He suggests that hope includes two features: we desire something we do not have (e.g., deficiency); and we desire something we believe we could or may gain (pg. 6). However, the other dimension of yearning (e.g., importance) is not included in his definition.

\subsection{Differentiation of Hope from Hopefulness}

\subsubsection{Definitions of Hope vs. Hopefulness}

Hope is distinguished from a related and often confused term hopefulness. This distinction resolves some of the confusion regarding the meaning of 'hope" and the definitions shown in Table 1.2. Hope reflects the degree of yearning for a (goal congruent future oriented) outcome appraised as uncertain, yet possible. Hopefulness reflects expectations regarding a future, goal congruent outcome (de Mello and MacInnis, 2005). The two terms have several similar constituent elements (future orientation, goal congruency), but differ in several fundamental respects.

Yearning is omitted altogether in the definition of hopefulness. One can be hopeful of outcomes for which yearning is intense (I am hopeful that my baby will be OK) or weak (I am hopeful that it would not rain tomorrow). In contrast, yearning is central to the definition of hope. Second, while hope is defined in terms of yearning, hopefulness is defined in terms of expectation levels. As used here, expectations reflect the perceived probability that the goal congruent outcome will occur, not uncertainty regarding whether an outcome will or will not occur or which potential outcomes could occur (Oliver and Winer, 1987). Also, while there is a nonlinear relationship between hope and certainty/uncertainty, the relationship between hopefulness and expectations is linear. Specifically, one becomes more hopeful that a goal congruent outcome will occur in the future as one's expectations are raised from 0 to 0.5 to 1.0. Confidence, optimism, and pessimism (as shown in Table 1.1) may in fact be regarded as points along a hopefulness continuum. When certain that a goal relevant outcome will occur, one feels confident or certain. When one has high expectations for a goal congruent outcome, s/he feels optimistic. When one believes that a goal congruent outcome is unlikely, one feels pessimistic. Finally, one feels hopeless when convinced that a goal congruent outcome will not occur.

Notably, hope and hopefulness are not necessarily related. The fact that one hopes something good will happen (yearns for it) does not mean that one is hopeful that it will. One can sincerely hope that one gets into a good college, but not be hopeful that they will be accepted. One can hope to win a sweepstakes, but not be hopeful of a win.

The last column in Table 1.2 suggests that definitions by Obayuwana et al. (1982), Haase et al. (1992), Pieper (1994), and Rycroft (1979) reflect the concept we label hope. Definitions by Snyder et al. (1996), Staats (1989), and Gelwick (1979) focus on what we call hopefulness. Stotland's (1969) definition appears to mix hope and hopefulness as it focuses on both elements of hope (importance) and hopefulness (expectations). We believe this mixing of the two concepts is a natural source of confusion, because while hope and hopefulness are conceptually distinct, they can operate jointly. Hence, a consumer who hopes a product will 
make her look more beautiful can also become more hopeful that it will. While a complete discussion of the concept of hopefulness and its relevance to consumer behavior is quite important, we focus exclusively on the concept of hope below.

\subsection{How is Hope Different from Other Concepts?}

Understanding hope as a construct is critical to future work on the topic. Accordingly, we detail below how it differs from potentially related constructs. A number of terms bear seeming relationship to hope, though they are not typically distinguished from hope.

\subsubsection{Expectations}

Expectations are perceptions of likelihood that reflect the perceived probability that an outcome will be achieved. Here the term expectations refer to outcomes, not attribute levels. Expectations can range from a high of 1.0 (where one is certain that the outcome will or has occurred) to 0.0 (where one is certain that the outcome will or has not occurred).

Several factors distinguish hope from expectations (MacInnis and de Mello, 2005). While we can expect that either goal congruent or goal incongruent outcomes will happen, we only hope for goal congruent ones. Unlike hope, expectations can also be independent of yearning as when one expects things that are not very important or desirable. For example, one may have strong expectations that one's pen will write without smudging, but it is doubtful that feelings of hope over the same outcome are intense. As noted in the above discussion, hope is also linked with general uncertainty, not a specific expectation level, as one can also hope for things that are uncertain but either expected or unexpected. 'Occasionally, something or someone is so important, so desired that belief and behavior are contoured to the possible, even when perceived probabilities are low" (Nunn, 1996, pg. 228). Finally, hope has stronger implications for motivation and action tendencies than expectations. Nowotny (1979) writes, 'Hope ... is much more bound up with life and active than with passive expectation" (pg. 148).

\subsubsection{Optimism/Pessimism}

Tiger (1979) defines optimism as "a mood or attitude associated with an expectation about the social or material future one which the evaluator regards as socially desirable to his [or her] advantage or for his [or her] pleasure" (pg. 18). According to this definition, optimism shares the goal congruent dimension of hope (MacInnis et al., 2004). Optimism shares another commonality with hope in that both concepts are future-focused (note Figure 1.1; e.g., Gillham et al., 2001, Bruininks and Malle, 2005).

If optimism and pessimism are regarded as points along a hopefulness continuum, as suggested above, hope differs from optimism/pessimism in ways previously described for hopefulness. Evidence that optimism/pessimism can be regarded as points along a hopefulness comes from Carver et al. (1994; see also Averill et al., 1990, Lazarus, 1991) who found that pessimists had low expectations (hence low levels of hopefulness) that the good outcomes would be realized while optimists had high expectations (hence high levels of hopefulness) regarding the future.

Optimism/pessimism can also differ from hope in several other ways. Lazarus (1999a) suggests a correspondence between hope on the one hand and realistic appraisal and hence acceptance of the possibility that the goal congruent outcome will not be realized given its uncertain nature, on the other. Optimism, instead, centers on Confidence in the likelihood of the goal congruent outcome and need not incorporate this realistic appraisal.

Unlike hope, which varies by situation, optimism is often characterized as an individual difference variable (see Scheier and Carver, 1985, 1987, Fitzgerald, 1979, Seligman, 1991, MacInnis et al., 2004). Several scholars (e.g., Lazarus, 1999a, Averill et al., 1990) believe that optimism/pessimism and hope can co-exist. 
For example, one can be pessimistic that a given outcome will happen, but still hope that it will. Lazarus (1999a) describes himself as a 'pessimist who hopes." One could also be both optimistic about the occurrence of an outcome and hope for its occurrence.

\subsubsection{Faith}

Hope is often used in the religion literature as something akin to faith. Like hope, faith deals with a goal congruent, future outcome. However, several factors differentiate hope from faith. Unlike hope, which is an emotion, faith is a belief about a future outcome. Second, faith is associated with high expectations, while hope can occur across a broad range of uncertain circumstances. One who has faith strongly believes that all will be well. One who hopes is less certain. Faith and hope also differ in what drives the possibility of the goal congruent outcome. A number of environmental factors may make one uncertain about whether a goal congruent outcome will occur (e.g., lack of certainty regarding degree of control over the outcome, lack of knowledge about how to actualize the outcome). With faith, sources of expectations tend to reside exclusively in forces (e.g., benign gods) outside of one's control.

\subsubsection{Desire}

Like hope, desire is a positive emotional state. Furthermore, just as desire is shaped by social and historical circumstances, need not subside with satiation, and is linked with motivation (Belk et al., 2003) so too does hope share these characteristics. However, desire and hope differ in several fundamental respects.

Desire is one of several dimensions of the yearning component of hope, and yearning is just one of several dimensions of hope. Lazarus (1999a) writes, "Although desire is an essential feature, hope is much more than this because it requires the belief in the possibility of a favorable outcome" (pg. 653). Hope is also distinct from desire in several other respects. Unlike desire, which is viewed as potentially involving a loss of control (Belk et al., 2003), hope does not seem relevant to the loss of control. Averill et al. (1990) also found that hope is future oriented, while yearning and desire need not be. For example, one can yearn for or desire to return to one's past, as is the case with nostalgia. Furthermore, while we tend to desire objects of all range of probable occurrence (Averill et al., 1990), Belk et al. (2003) suggest an inverse linear relationship between desire and probability of occurrence -we tend to have the greatest desire for things that are least likely to occur or are even impossible, as might be the case with fantasy and dream. Hope does not exist when goal congruent outcomes are viewed as impossible or completely certain. We also desire things that vary across a range of importance. Averill et al. (1990) empirically observed that hope varies more with the importance of the goal congruent outcome than does desire. Desires also tend to be tangible, concrete, situation-specific and rooted in pleasure-focused, material and sexual objects. Desire is also insistent, can involve obsession, and leads to fear of being overpowered (Belk et al., 2003). Hope is less so. Desire also often has an avoidance or discomfort component, as giving in to desires (e.g., eating, extra-marital sex) may lead to aversive outcomes (weight gain, divorce) (Belk et al., 2003). Hope is more expansive as it also includes outcomes consistent with social and moral values (e.g., I hope the refugees receive humanitarian aid) and hence less likely to have an aversive component (Averill et al., 1990).

\subsubsection{Involvement}

A term of considerable import in consumer behavior, but relative lack of precision in conceptualization is involvement. Park and Mittal's (1985) definition of involvement has gained relatively widespread usage. They define involvement as goal directed arousal." One can be involved in many different things--an ad, a product category, a medium, or a decision. Moreover, a consumer who hopes for a goal congruent outcome (e.g., profiting from the stock market) may be highly involved in many activities (e.g., reading prospectus sheets, consulting with friends and brokers, and evaluating the diversity of her portfolio) that suggest high levels of involvement (MacInnis and de Mello, 2005).

While involvement in ads, product categories and decisions may be related to hope, the two concepts are 
quite distinct. Involvement reflects the extent of arousal or energy that the consumer experiences. Hope is more than just arousal or energy. It is a positive emotion. It is also an emotion attached not to an ad, a message, a brand, medium or decision, but rather the goal to be achieved (MacInnis and de Mello, 2005). Hope is linked to outcomes achieved from making the decision. Involvement is also a psychological state that relates to things in the present. Hope deals with the future. Finally, while hope is fundamentally wrapped up in uncertainty about possible futures, uncertainty is not part of the definition of involvement.

\subsubsection{Wishing}

Hope seems related to constructs like wishing. Like hope, wishing reflects yearning for a goal congruent outcome. Notably though, hope is more clearly related to motivation and action tendencies than is wishing. We tend to actively approach hoped for objects. Hope is also more strongly linked to perceived possibility. We hope for outcomes that are possible, however, we often wish for things that are impossible. Unlike wishing, hope often involves consideration that good things may not happen and that the future might well be negative (Lazarus, 1999a). Wishing also has a fantastic dimension to it. One may wish that she could turn into a bird and fly away from traffic, but it is unlikely that a consumer hopes to turn into a bird. While wishing can refer to both the future ("I wish I could go to Africa next year"), and the past ("I wish I had done it before"), hope only refers to the future. Finally, we tend to wish for outcomes over which we have little control, but hope for things that are at least possible by virtue of the fact that we could control their occurrence. For this reason, wishing is more closely related to the concept of fantasizing than to hope.

\subsubsection{Nostalgia and Joy}

Like nostalgia and joy, hope is a positive emotion related to the achievement of a goal congruent outcome. Table 1.1 shows that the differences between hope and these other emotions concern their temporal orientation. If hope is achieved, we feel joy. When joy has passed and we have memories of this joyful time, we feel nostalgia.

\subsection{Emotional Concomitants of Hope}

\subsubsection{Anxiety}

While hope is distinct from various terms and emotions, some emotions can co-occur with hope as suggested in Table 1.1 and the propositions in Table 1.3. One is anxiety. Uncertainty regarding something yearned breeds anxiety (Lazarus, 1999a). Uncertainty without yearning does not breed anxiety. Nor does yearning with certainty breed anxiety. Hence anxiety is often present with hope because the yearned for outcome is uncertain.

\subsubsection{Fear}

The uncertainty and anxiety associated with hope, coupled with its goal congruent nature, makes it possible to link hope with another emotion -fear. Spinoza (1960) said, 'Fear cannot be without hope, nor hope without fear." To illustrate their potential co-occurrence, consider the outcomes shown in Figure 1.1. As shown there, outcomes can be positive or negative and these outcomes can either occur or not occur. Consider fist a case in which the consumer faces the occurrence of a positive outcome (e.g., winning the lottery) and then imagines that this outcome might occur or might not. In this situation, the consumer likely feels just hope, without accompanying fear because in a benign environment, the lack of occurrence a positive outcome leads to a benign, favorable status quo. The consumer is no worse off than before.

Next, consider a situation in which the consumer faces the occurrence of a state that is negative and that might or might not occur (e.g., having premature wrinkles). In this situation, the consumer may feel fear 
regarding the occurrence of the negative state coupled with hope that the state can be avoided. Thus, the rows of Figure 1.1 show that hope is coupled with fear when consumers' focus of attention is on the non-occurrence of a negative outcome versus the occurrence of a positive one.

The columns of this figure likewise reveal the potential co-occurrence of hope and fear. Imagine a consumer who fixes on the occurrence of a future outcome that could be either positive (e.g., will pass the test, have a healthy baby, live to see my children grow up) or negative (I will fail, have an ill child, die before mg children grow up). Doubt regarding the valence of the outcome coupled with uncertainty leads the consumer to experience hope and fear simultaneously. Note, these emotions focus on different outcomes Mope of passing; fear of failing but because both scenarios are imagined, both emotions are evoked. (3)

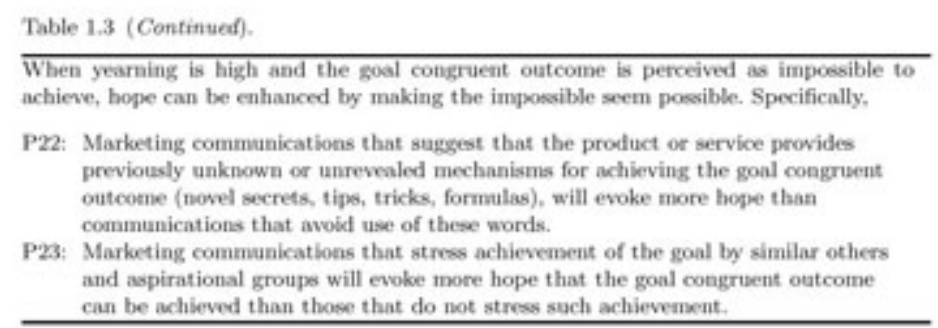

The forgoing raises interesting questions regarding the relationship between hope and fear as it relates to framing and decision-making under risk. Tversky and Kahneman (1981) posit that the manner in which a decision problem is framed affects consumers' perceptions of a risky decision. Their value function also reveals that in making risky decisions, losses loom larger than gains (see also Hardie et al., 1993). The scenarios in Figure 1.1 suggest that the extent to which consumers experience hope mixed with fear may depend on how the situation is framed (either by consumers or by marketers). If a situation is framed as a positive outcome happening vs. not happening, consumers may experience hope with little accompanying fear. If the situation is framed as a positive outcome happening vs. a negative outcome happening, consumers may experience hope mixed with fear since losses loom larger than gains.

One wonders whether consumers will have more intense fear for the occurrence of a goal incongruent outcome happening (my house might catch on fire) than hope for the corresponding goal congruent outcome (my house would not burn up in a fire). As evidence of such potential asymmetries, Showers (1992) asked subjects to focus on possibilities for a negative or positive future social interaction. All subjects felt worse after focusing on a negative than positive future possibility. Potential asymmetries in fear vs. hope may lead consumers to avail themselves of products and services like life insurance policies, premarital agreements, homeowners insurance, or extended warranties to protect against the occurrence of negative yet uncertain outcomes.

(1) Lazarus actually suggests that hope has a secondary appraisal of goal incongruent because it often arises from a negative or aversive situation (e.g., I may have cancer, I hope I do not). While possible, we focus on the congruence of the outcome, not the precipitating factor eliciting the emotion. With hope, the outcome is consistent with and hence congruent with goals. Furthermore, while hope may arise from aversive situations, it can also arise from relatively neutral (status quo) conditions as when one hopes one wins the lottery or hopes that a product will turn the current (OK) self into a better self (see Figure 1.1).

(2) Roseman (1984), Roseman et al. (1990) developed a similar typology, though the dimensions they described do not exactly map those we note since his typology was developed to characterize all emotions, not just the dimensions that characterize one emotion like hope.

(3) Interestingly, while hope exhibits a complex relationship with fear, its relationship with hopefulness is clearer. As one become more hopeful that a positive outcome will happen, fear that a negative outcome will occur should decline. Furthermore, the relationship between hopefulness and anxiety is straightforward. Since hopefulness is related to expectations and expectations relate to anxiety, one should feel less anxious as 
one becomes more hopeful that a goal congruent outcome will occur (e.g., a positive outcome will occur or a negative outcome will not occur).

Table 1.1 The dimensions of hope and its relationship to other emotions.

Possibility

(perceived probability)

of occurrence

Strong yearning for

it occurring

Future

$\begin{array}{ll}\text { Joy/confidence } & \text { Pleasure/confidence } \\ \begin{array}{l}\text { HOPE/optimism/ } \\ \text { anxiety }\end{array} & \text { Optimism } \\ \text { Hope/anxiety } & \text { Uncertainty } \\ \text { Hope/pessimism/ } & \text { Pessimism } \\ \text { Hopelessness/ } & \text { Resignation/ } \\ \text { confidence } & \text { confidence }\end{array}$
Happiness/joy/relief/ Contentment pride (if due to perceived efforts) Disappointment/anger

Weak yearning

for it occurring
Present
Did happen
Did not happen
Will happen (1.0)
(certainty)

Past

Did happen

Did not happen

$\begin{array}{ll}\text { Nostalgia/relief/ } & \text { Fondness/relief } \\ \text { regret (if due to } & \\ \text { one's own actions) } & \\ \text { Depression/sorrow/ } & \text { Sadness } \\ \text { regret (if due to } & \\ \text { one's own actions) } & \end{array}$

Note: Occurrence of a goal congruent outcome

(I win the lottery/I do not have cancer).

Table 1.2 Comparing the definition of hope and hopefulness to other definitions.

Proposed Definition--The degree of yearning for a (goal congruent Future) outcome appraised as uncertain but possible.

Obayuwana et al. (1982)--The

feeling that what is desired is

also possible or that events may

turn out for the best.

Haase et al. (1992)--An energized mental state involving feelings of uneasiness or uncertainty and characterized by a cognitive, action-oriented expectation that a positive future goal or outcome is possible.

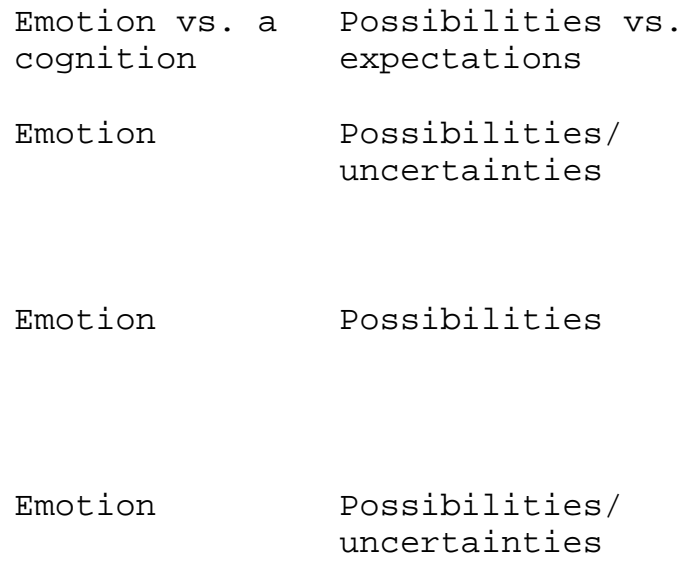




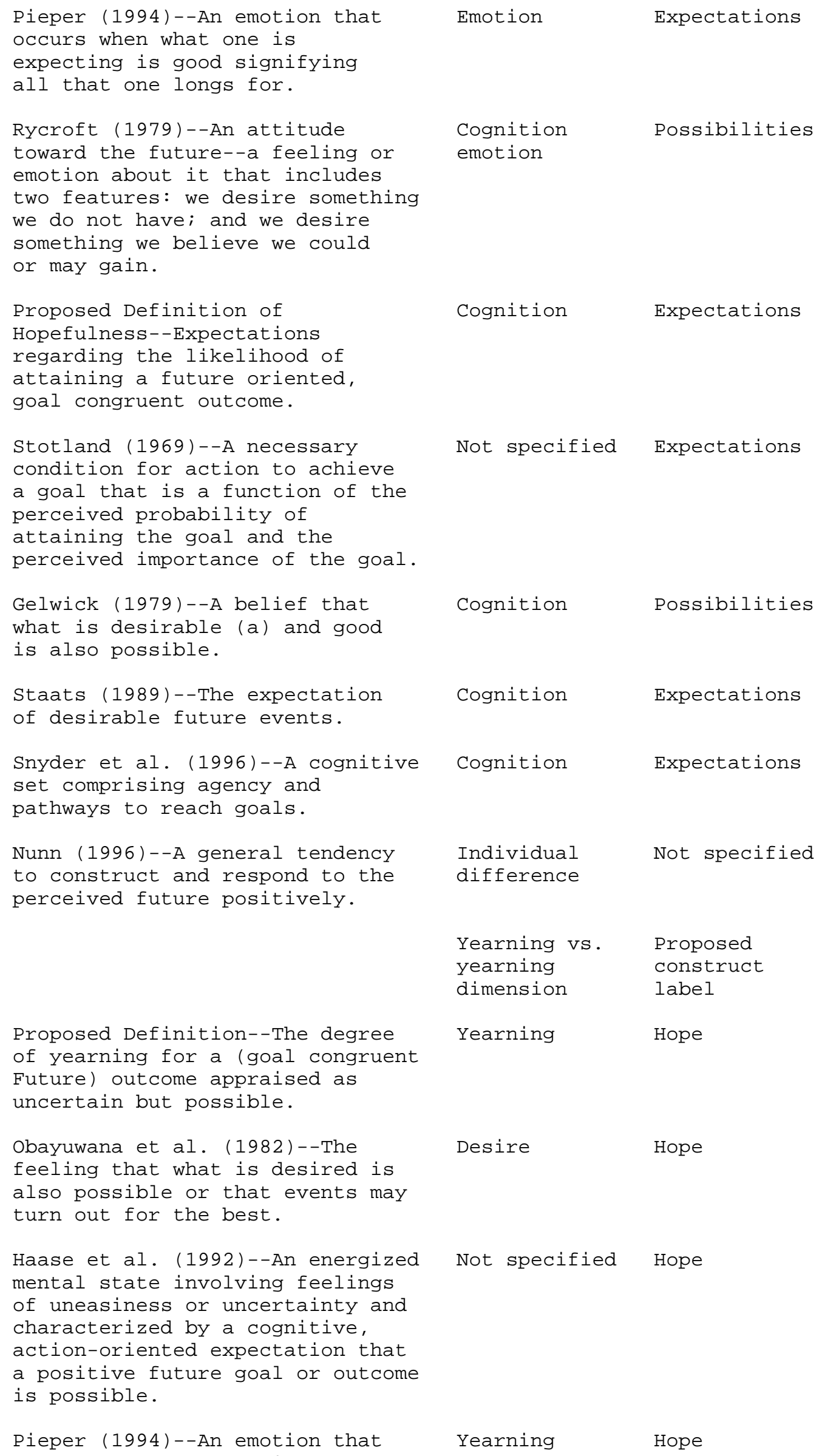

Cognition

emotion

Cognition

Expectations

Not specified Expectations

Cognition

Possibilities

Cognition

Expectations

Cognition

Expectations

Individual

Not specified

difference

$\begin{array}{ll}\text { Yearning vs. } & \text { Proposed } \\ \text { yearning } & \text { construct } \\ \text { dimension } & \text { label }\end{array}$

Yearning Hope

Desire Hope

Not specified Hope

Yearning Hope 
all that one longs for.

$\begin{array}{lll}\text { Rycroft (1979)--An attitude } & \text { Desire } & \text { Hope } \\ \text { toward the future--a feeling or } & \text { deficiency } & \\ \text { emotion about it that includes } & & \\ \text { two features: we desire something } & & \\ \text { we do not have; and we desire } & & \\ \text { something we believe we could } & & \\ \text { or may gain. } & \text { N/A } & \text { Hopefulness } \\ \text { Proposed Definition of } & & \\ \text { Hopefulness--Expectations } & & \\ \text { regarding the likelihood of } & & \\ \text { attaining a future oriented, } & & \text { Mixes hope } \\ \text { goal congruent outcome. } & \text { Importance } & \\ \text { Stotland (1969)--A necessary } & & \\ \text { condition for action to achieve } & & \\ \text { a goal that is a function of the } & & \\ \text { perceived probability of } & & \\ \text { attaining the goal and the } & & \\ \text { perceived importance of the goal. } & & \end{array}$

Gelwick (1979)--A belief that what is desirable (a) and good is also possible.

Not specified Hopefulness

Staats (1989)--The expectation of desirable future events.

Not specified Hopefulness

Snyder et al. (1996)--A cognitive set comprising agency and

pathways to reach goals.

Nunn (1996)--A general tendency to construct and respond to the perceived future positively.

Not specified Hopefulness

Not specified Dispositional hopefulness

(a) The term "desirable" means "goal congruent," and should not be confused with the amount of desire or yearning one has for the goal congruent outcome.

Table 1.3 Propositions related to hope.

Propositions Related to Potential Concomitants of Hope

P1: When feelings of hope are intense, consumers will also experience feelings of anxiety, particularly when consumers perceive that the outcome could be either goal congruent or goal incongruent.

P2: The relationship between hope and fear depends on whether the consumer is focused on the occurrence or lack of occurrence of an outcome and whether the outcome is regarded as positive or negative (from Figure 1.1):

P2a: When consumers focus on a negative outcome, they will experience fear that the outcome will occur coupled with hope that it will not.

P2b: When consumers focus on a positive outcome, they will experience hope that the outcome will occur but not fear that it will not.

P2c: When consumers focus on the occurrence of a positive vs. a Negative outcome, they will experience hope that the positive outcome will occur and fear that the negative outcome will not.

P2d: When consumers focus on the lack of occurrence of a positive vs. a negative outcome, they will experience hope that the negative outcome 
will not occur, but not fear that the positive outcome will not occur.

P3: Consumers will experience more intense levels of fear in response to the occurrence of a negative outcome than intense levels of hope for the failure of a negative outcome to occur.

P4: Optimism/pessimism can be independent of hope. Consumers with intense feelings of hope may be optimistic or pessimistic regarding the occurrence of the goal congruent outcome.

Propositions Related to What Consumers Hope For

P5: Consumers spend considerable time thinking about their hoped for selves (and products related to them) and spend less time thinking about their feared selves, particularly at young ages.

P6: When consumers activate a future self, they are more likely to activate a hoped for self than an expected self.

P7: When consumers evaluate a product's relevance to their self-concept, they are more likely to evaluate its relevance to their hoped for self vs. their actual self.

P8: The extent to which consumers hope for outcomes in the spiritual, societal, achievement, etc domains varies as a function of age, transitions, and life circumstances.

P9: Consumers will have more intense hoped for selves, hoped for outcomes, and will have more intense hope to acquire new products when they are engaged in transitions than when they are not.

P10: Consumers hope for outcomes in a variety of life domains--spiritual, societal, achievement, interpersonal, personality, economic, physical, etc., though the domains vary in salience over the life course and across cultures.

P10a: Hope for physical safety and security is most intense among the very young. Hope for interpersonal relationship is most intense among adolescents and the very old, hope for achievement is greatest among young adults, hope for economic success is greatest at midlife.

P10b: Consumers in Western cultures have more intense hope for goals in The achievement, economic and physical domains than consumers in Eastern cultures. Consumers in Eastern cultures will have more intense hope for goals in the interpersonal and societal domain than consumers in Western cultures.

P10c: Cross-cultural differences exist in the assessment of what consumers should hope for.

Propositions Related to Outcomes of Consumer Hope

P11: The more consumers hope to attain a goal congruent outcome, the more likely they will be to be to engage in biased processing (e.g., use (1) positive misinterpretation, (2) selective focusing/attending, (3) selective evidence gathering, (4) misinterpret incomplete and unrepresentative data, (5) re-write their histories of success and failure, and (6) utilize the false consensus effect) and hence deceive themselves regarding a product or service's ability to help them achieve that outcome.

P12: The more consumers hope for the attainment of a goal congruent outcome, the more likely they will be to engage in risky behaviors designed to attain that outcome.

P12a: The relationship between hope and risk taking behavior is mediated by biased processing. 
P13: When the product is successful in achieving the goal congruent outcome, the relationship between consumers' hope for the outcome and satisfaction and joy will be intense and positive.

P14: When the product is unsuccessful in achieving the goal congruent outcome, there is only a weak negative relationship between hope and product satisfaction.

P15: Consumers who do and do not achieve their hopes through consumption will experience lower levels of self and life satisfaction and happiness than consumers who attempt to achieve their hopes through other mechanisms (e.g., religion).

P16: The more consumers hope to achieve goal congruent outcomes through the marketplace, the more materialistic they will become.

P17: The more consumers' hopes in various life domains are dashed, the more materialistic they will become.

P18: The more materialistic consumers are, the more they will use the marketplace as a source of attaining future hopes.

Propositions Related to Marketing Tactics that Evoke Hope

When an outcome is goal congruent and perceived as possible, hope will be enhanced by marketing communications that enhance yearning for the outcome. Specifically,

P19: The more marketing communications (a) evoke positive fantasy imagery, or (b) suggest that a product or service can resolve an approach avoidance conflict, the more consumers will hope that the goal congruent outcome will be achieved.

P20: The more marketing communications link usage of the product or service with higher order goals, the more consumers will hope that the product will be instrumental to the achievement of those goals.

P21: The more marketing communications that imply that goal congruent outcomes can be achieved by only a few people or directly point out a deficiency in the consumer, the more the consumer will hope to achieve a goal congruent outcome related to deficiency resolution.

When yearning is high and the goal congruent outcome is perceived as impossible to achieve, hope can be enhanced by making the impossible seem possible. Specifically,

P22: Marketing communications that suggest that the product or service provides previously unknown or unrevealed mechanisms for achieving the goal congruent outcome (novel secrets, tips, tricks, formulas), will evoke more hope than communications that avoid use of these words.

P23: Marketing communications that stress achievement of the goal by similar others and aspirational groups will evoke more hope that the goal congruent outcome can be achieved than those that do not stress such achievement. 


\section{What do consumers hope for?}

Since hope is tied to yearning for a possible, yet uncertain future oriented goal congruent outcome, understanding what consumers hope for should be revealed by understanding what goals they End congruent and hence for which they yearn. We consider what consumers hope for by describing the two dimensions identified in Table 2.1 (1) the goal level at which hope is experienced and (2) the consumption domain in which it is experienced. Though prior research in this area is sparse, building on MacInnis et al. (2004) we develop a preliminary (though not necessarily comprehensive) characterization based on these dimensions.

\subsection{Levels of Hope}

\subsubsection{Hoped for Selves}

At a macro level are goals dealing with life themes and values (e.g., safety, security, family, perfection, achievement, and spirituality) (Huffman et al., 2000) that may be reflected in various conceptions of the self.

Markus and colleagues (e.g., Markus and Wurf, 1987, Markus and Nurius, 1986, Markus and Ruvolo, 1989, Cross and Markus, 1991) suggest that the self-concept is multi-faceted, comprised of a variety of selves such as a hoped for self, an expected self, an actual self, and a feared self. These various selves are related to the future orientation, goal congruence, and uncertainty -dimensions described earlier. The actual self is a present self while the other three are future selves. While hoped for selves are rooted in the occurrence of goal congruent outcomes, feared selves are rooted in the occurrence of negative goal incongruent outcomes (see Figure 1.1). Expected selves deal with selves that are likely (associated with very high expectations). Hoped-for and feared selves deal with selves that are possible yet uncertain. Expected selves deal with selves that are probable.

The literature on hoped, feared and expected selves is quite relevant to consumer research as suggested by the propositions in Table 1.3. Specifically, that research finds that future, present, and past selves may vary in salience, centrality and importance to the individual. Conceptions of one's future (and hence hoped for) self can be quite salient. McGuire and Padawer-Singer's (1976) study revealed that $65 \%$ of the 12-year old students reported thinking about themselves in the future a great deal of time. They also found that the ratio of positive to negative selves was 4:1. These results suggest that at least for young girls, hoped for selves are highly salient and tend to be more accessible than feared selves. Markus and Ruvolo (1989) propose that in many cases, individuals give relatively little independent weight to their chance of actual success and instead base their decisions and actions on how much they would yearn for a given outcome. Hence, when consumers activate a future self, they may be more likely to activate a hoped for self than an expected self. Markus and Nurius (1986) also write, 'Many important decisions involve a process of imagining the self under various outcomes. Yet in some decisions, such as the decision to purchase a particular car or a certain cologne, a possible (and hoped for) self, rather than the current self will be envisioned and guide the process" (pg. 966). Thus when consumers evaluate a product's relevance to their self-concept, they may be more likely to evaluate its relevance to their hoped-for than their actual self.

\subsubsection{Hoped For Outcomes}

At a less abstract and more concrete level, consumers deal with the current problems or specific tasks on which they are working (Huffman et al., 2000). As Table 2.1 shows, these problems and tasks give rise to hoped for outcomes, and the goals consumers strive to achieve is not so abstract but more situationally-bounded. Consumers may hope to achieve certain outcomes like becoming healthy, looking 
more beautiful, feeling more confident, winning the lottery, building a more intimate relationship with kids, Ending a cure for AIDS, or overcoming diabetes. Since many outcomes consumers hope for can be easily described at the level of current concerns, they are pivotal for the concept of a goal congruent outcome."

\subsubsection{Hoped for Products}

At an even more micro level, consumers hope to acquire products. Averill et al. (1990) found that college students asked to pick an episode that occurred over the past year that reflected hope (and not simply want or desire) included material objects (e.g., a new car) as objects of hope. The reason why consumers hope for products may be tied to conceptions of the future and future possibilities. McCracken (1990) suggests that the meaning surrounding consumer goods can be displaced to the future (or the past). Displaced meaning, he writes, sustains hope. Hope for a product is in essence displaced because the product's meaning is wrapped up in the future goals to which it is relevant. For example, a consumer may hope to buy a new Accord, buy some new clothes, or visit a spa as the meaning of these consumption practices are tied to such future states as achieving, looking stylish, or feeling relaxed. Another may hope to receive a wedding ring as it symbolizes marital happiness and stability. Children hope for toys from Santa as toys symbolize future fun and enjoyment. The good is hence the embodiment of a set of displaced meanings. In support of these ideas, the journal of a gold rush prospector noted that the promise of gold was wrapped up in money to marry his fiancee (Hamilton, 1978). Belk (1996) writes, 'perhaps for all of us in one way or another, some of our strongest and most readily available hopes for transcendent and transformational experiences lie in consumer goods and services ... People need nourishment for their fantasies and many of us need reified artifacts that act as symbols of these hopes" (pgs. 102-103).

\subsubsection{Interactions Among the Levels}

Hoped for selves, hoped for outcomes, and hoped for products reflect mutually reinforcing and interdependent goal levels (MacInnis et al., 2004). Consistent with work on the means-end chain analysis (e.g., Gutman, 1982, Reynolds and Gutman, 1988), products are bundles of attributes that achieve benefits. Consumption of the product and its attributes provides the means for achieving benefits, which facilitate the achievement of outcomes and current concerns consistent with consumers' values, life themes, and hence hoped for selves. Analogously, through the process of abstraction, higher level hoped for selves shape hoped for outcomes and motivate the search for products whose attributes and benefits are relevant to current concerns and goal congruent outcomes (Huffman et al., 2000). Thus, the consumer whose hoped for self involves being healthy may hope to quit smoking and hope to obtain products or services that can achieve this outcome and further the development of the hoped for self.

\subsubsection{Evolution of Hoped for Selves, Outcomes and Objects}

Consumers' hoped for selves, and the outcomes and products with which they are associated are, as suggested by the propositions in Table 1.3, likely in constant flux. Mergenhagen (1995) writes that consumers undergo a number of important and culturally prescribed transitions, moving from such states as a high school to a college student, a student to a professional, a single to a married person, one who is childless to one who has children, from marriage to divorce to remarriage, from working to retirement and so on. Cross and Markus (1991) found that marital, family and career transitions stimulated 18-24-year olds' hoped-for selves.

Perhaps this is so since transitions have a number of characteristics that map the constituent elements of hope. They involve future achievements that have yet to be realized. Changes often precipitate movement into new roles; a movement often fraught with uncertainty in the achievement of roles and specify outcomes (Wicklund and Gollwitzer, 1982, Solomon, 1983). Change, marked by transitions, also opens the door to new possibilities, making what seemed previously impossible now possible. Change precipitated by the fall of Communism in Eastern Europe, for example, stimulated consumers' hope for freedom and the betterment of life Brown (1994). Transitions can also make a previously unimportant outcome important and hence affect yearning for that outcome (Averill et al., 1990). Men have more intense hope for power at midlife than at 
other times in their lives (Veroff et al., 1984), perhaps because age, career, and occupational transitions enhanced the centrality of power to self definition at midlife. Many transitions are goal congruent as they represent the movement toward goal congruent outcomes like achievement, freedom, or a new relationship. The fact that transitions entail many of the factors that underlie hope suggests that transitions are a rich source of hope for consumers.

That changes and transitions stimulate hope also suggests increased reliance on consumer products and services as aids to role transitions. Solomon (1983) writes that the uncertainty and anxiety that surrounds movement into new roles heighten reliance on role stereotypic products that both communicate one's new role and provide reflexive evaluation from others regarding role performance. For example, new hairstyles allow consumers to create a new (and potentially hoped for) identity consistent with their burgeoning and hoped for self-image (McAlexander and Schouten, 1989), while cosmetic surgery is means of identity reconstruction, which facilitates movement from old roles to presumably better 'hoped for selves" (Schouten, 1991).

\subsection{Domains of Hope}

In addition to the levels of entities about which consumer hope can be organized, we can also consider the specify domains of life in which hope arises. Though little research has been done in this area, we develop a preliminary taxonomy of domains shown in Table 2.1. (1) Several of these domains are explored below.

\subsubsection{Spiritual Domain}

One domain relates to spiritualism and the hope for life after death. Hope for salvation, redemption, the afterlife, heaven, angels, miraculous cures, divine intervention and the like characterize hope in the spiritual domain. Religion has traditionally channeled our need for meaning and purpose through beliefs in the spiritual world. Hope is also experienced through televangelism, or "the business of popular religion" (Schultze, 1991). Spiritualism is not limited to religion though. Current society displays a need for a spiritual or transcendental view of the universe, regardless of adherence to a particular religion. The New Age industry has grown exponentially in recent years, in large part driven by consumers' needs to End a spiritual connection in a non-religious context. Rycroft (1979) indicates, 'if we are religious, this future about which we may have hope is not in this world or in this life, but in heaven and in the after-life. But if we are not religious, in the traditional Christian sense, the future for which we have hope can only be in this world and our sources of hope can only reside in our assessment of what the worldly future will hold" (pg. 7).

\subsubsection{Societal Domain}

One is hope for societal goals such as the enhancement of social welfare and ensuring the peaceful continuation of life, as we know it. In one of the few systematic studies of domains of hope, Cantrill and Roll (1971) took stock of the hopes (and fears) of Americans just following the Vietnam War. Among those listed were a set of hopes for the world or nation, including hope for (1) peaceful and harmonious living, (2) economic security, (3) public health, and (4) the environment. As Table 2.1 indicates, consumers who hope for the non-destruction of our environment may become members or donate to charitable causes like the Sierra Club and GreenPeace, vote for the Green Party, buy environmentally friendly products, and boycott furs, fluorocarbon products, biogenetically engineered food and companies that produce toxic products. Those who hope for world health support movements and organizations designed to fight the spread of AIDS, promote birth control, and research cures for cancer. Hope for the betterment of society hence affects the marketplace by virtue of consumers' boycotting, fundraising, and purchasing power.

\subsubsection{Achievement Domain}

The achievement domain is yet another context in which hope is elicited. Averill et al. (1990) asked students to indicate things they hoped for. One of the categories mentioned was hope for achievement in artistic, 
athletic, or academic pursuits. Other achievement contexts include wealth, recognition, status, perfection, and so on. Moreover, a number of industries give rise to opportunities to achieve these goals. Consumers who hope for recognition and 'being on top" may be diehard fans of sports teams, as strong team affiliation means that the team's win is one's personal win. Those who hope for educational advancement likely use such products and services as colleges, private schools, Kaplan study methods, and tutors. Hope for recognition and status prompts consumption of high-end cars, luxury homes and appliances, luxury travel, and designer clothing. Even the exercise, medical and dieting industries provide a context for achievement as some consumers view the body and such goal congruent outcomes as good looks, health, and thinness as domains of achievement (Woodman, 1982, Brumberg, 1998). Consumers with intense hope for achievement through the body may, for example, become body builders, triathletes, compulsive exercisers or anorexic.

\subsubsection{Economic Domain}

Cantril and Roll's (1971) study of the hopes and fears of Americans also identified hopes relating to personal economic situations such as wealth, a better standard of living, home ownership, employment, and freedom from inflation. As with the domains above, a number of industries cater to consumers' hope in this domain. Financial planners and advisors offer expert advice that is important for consumers who hope for wealth. These consumers may also invest in the stock market, acquire real estate, buy lottery tickets, and gamble. Real estate agents, banks, credit reporting services, and mortgage brokers are intimately involved in consumers' hope for better homes. Consumers who hope for economic stability and fear future disasters may invest heavily in insurance.

\subsubsection{Interpersonal Domain}

Averill et al.'s (1990) study of hope also suggests that consumers experience hope in areas relating to romance and relationships with others (Table 2.1), as one may hope to be a better parent, friend, lover, partner, son, and so on. Although interpersonal relationships need not develop within the context of the marketplace, the consumer marketplace can be an important one in which hope is evidenced. Hope for a partner may prompt usage of dating services, purchase of self-help books, or consumption of TV shows that suggest that dating and marrying rich are possible. Those who hope for a more enjoyable and gratifying love life may buy sexual aids and provocative lingerie, visit sex therapists, frequent restaurants that promote romantic dinner, and/or book vacations or cruises and hideaways that promise to give couples needed intimate time. Consumers who hope for better interpersonal relationships may visit therapists (psychiatrists, social workers), who offer individual, group, and family counseling for resolving difficult interpersonal relationships with bosses, children, partners, and parents, give gifts (flowers, diamonds) or hand down personal possessions to family members (Folkman, 1999). They may similarly buy self-help books that advise on keeping relationships intact and managing them when they fall apart through death, divorce, or other losses. The hope for maintaining long distance relationships spurs the greeting card, long distance telephone service, and email industries. Gift giving also provides a context for conveying the meaning about relationships and hopes for its continuation.

\subsubsection{Personality/Emotional Domain}

When asked to pick an episode that occurred over the past year that reflected hope, Averill et al.'s (1990) respondents also mentioned hope for personality changes. An introverted consumer may hope to become more outgoing and social, a consumer who is lacking self-assurance more confident, and a consumer who is on irresponsible spending streak more frugal. As with the interpersonal domain, the marketplace provides a rich context for the satisfaction of hope in this domain, through, for example, self-help books that help mastering happiness and becoming effective, psychotherapy practices, pharmaceuticals (Prozac, Effexor, Paxil), dietary supplements (St. John's wort and kava-kava), and alternative/new age practices (e.g., light therapy, sound therapy, meditation, and such associated accoutrements as incense and mediation mats).

\subsubsection{Physical Domain}


Finally, hope is related to the physical domain. Consumers feel hope for beauty, sexiness, safety, and health, among other things. As with other domains, the marketplace may offer hope for the achievement of such outcomes. Consumers who hope for beauty and sex appeal may diet, visit beauty salons, or utilize such treatments as abdominoplasty, facelifts, tummy tucks, breast enhancement, penile enlargement /lengthening, hair transplants, laser hair removal, skin care products, specialty hair products, beauty parlors, skin treatment centers, and the like. It is interesting that services such as penile lengthening are listed under 'pelf-enhancement" in lifestyle publications, implying that this type of remodeling surgery not only fixes 'physical deficiencies," but also creates a new, improved self. Consumers also buy into herbs, minerals and drugs that pledge to reduce appetite, burn fat, increase stamina and heighten sexual potency, concentrate or redistribute energy, and detoxify the body. The dieting industry (diets, cooking shows, diet books, calorie counters), supplement industry (Phen Phen), medical industry (diet pills, jaw wiring), and exercise industries (personal trainers, gyms, home exercise equipment, home videos, TV shows on exercising, sporting goods) promise the successful outcome of a slim and well-toned body, and hence cater to consumers' hope for these goal congruent futures.

\subsubsection{Salience of Domains Across the Life Span}

The salience of these domains of hope may vary dramatically across the life span since goals and yearning for goal congruent outcomes likely varies greatly by age. Though research on this specific point is scarce, Cross and Markus (1991) examined individuals' hoped and feared selves at different points in their life span. They found that hoped for family and occupational selves became less prevalent over the life cycle while physical and lifestyle hoped for selves became more prevalent. One might surmise then that hope for physical security may be primary among the very young, hope for being cool and fitting in intense among adolescents, hope for achievement intense for young adults, hope for economic success intense among consumers at midlife, and hope for physical health most intense among the elderly.

\subsubsection{Salience of Domains by Culture}

It is possible that across cultures consumers differ in what they hope for. Hofstede's influential cross-cultural study $(1983,1997)$ of 50 countries and three regions identified four dimensions that characterize different cultures: power distance, collectivism/ individualism, femininity/ masculinity, and uncertainty avoidance.

While Hofstede's dimensions do not directly address the concept of hope, they hint that the selves, outcomes, and objects consumers hope for may vary by culture. One might surmise that given differences in collectivism vs. individualism, uncertainty avoidance, and masculine/feminine orientation, Western consumers are more likely than Eastern consumers to hope for outcomes in the achievement, economic, and physical domains, while Eastern consumers are more likely to hope for outcomes in the societal and interpersonal domains. Relatedly, hoped-for selves are bound to differ in individualistic countries, where self-actualization is the ultimate goal, than in collectivist countries, where goals focus on harmony and consensus in society.

To date, the authors are aware of only one study that relates to cross-cultural differences in hope. That study (Averill et al., 1990) examined not what consumers hope for, but rather what they desire, but feel they should not hope for. As such, it examined normative issues in the appropriateness of hope. The target cultural groups were Americans and Koreans. Americans were more likely to desire but feel they should not hope for material objects, interpersonal relationships and short-term achievements than Koreans since they felt that their goals in these domains were unrealistic, shortsighted, and interfered with other more pressing obligations. In contrast, significantly more Koreans than Americans indicate that they desired but should not hope for freedom from social and personal obligations and more hedonic pursuits. The reasons they gave for not hoping for these outcomes were that they were immoral, going against personal or social values, or failing to meet personal or social obligations. Normative appropriateness of what consumers hope for may be tied not only to culture, but also religion. While Christianity holds hope as a primary theological virtue, 
Averill (1991) writes that Confucianism appears to not have recognized hope. Among people who practice Zen philosophy, hope may be even disavowed. To hope is to focus on the future (not the here and now) and to focus on what one does not have (as opposed to what one has).

(1) These domains reveal the specific 'hopes" that consumers have. When one 'has hopes," one envisions a goal congruent future outcome that is uncertain and yearned. Hence 'having hopes" reflects a stage of goal assessment that sets the stage for the elicitation of the emotion of hope. Moreover, while consumers can feel hope for goal congruent outcomes in these domains, they can also experience varying degrees of hopefulness that this outcome will be realized. Hence these domains are also relevant to the study of hopefulness.

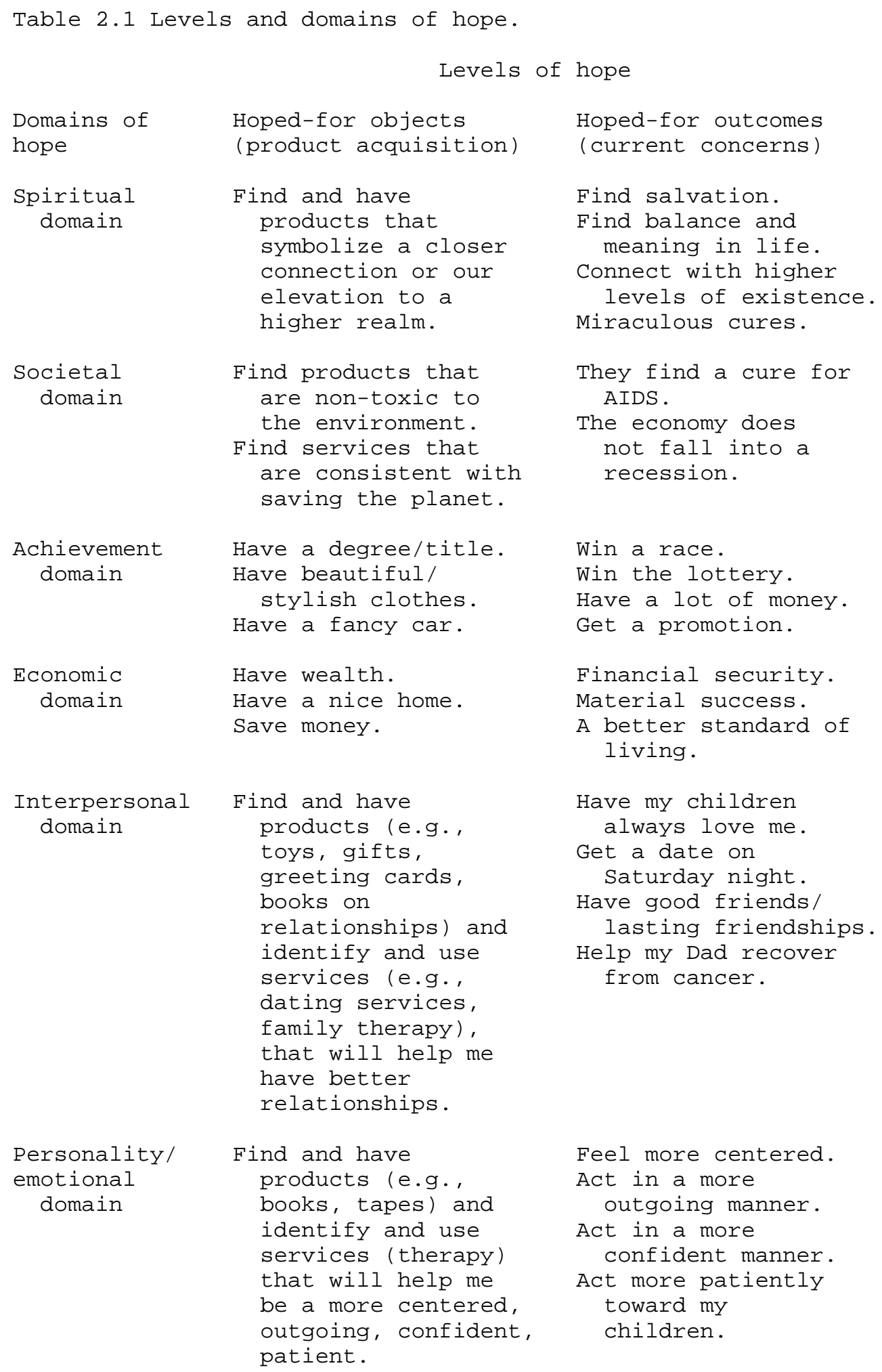




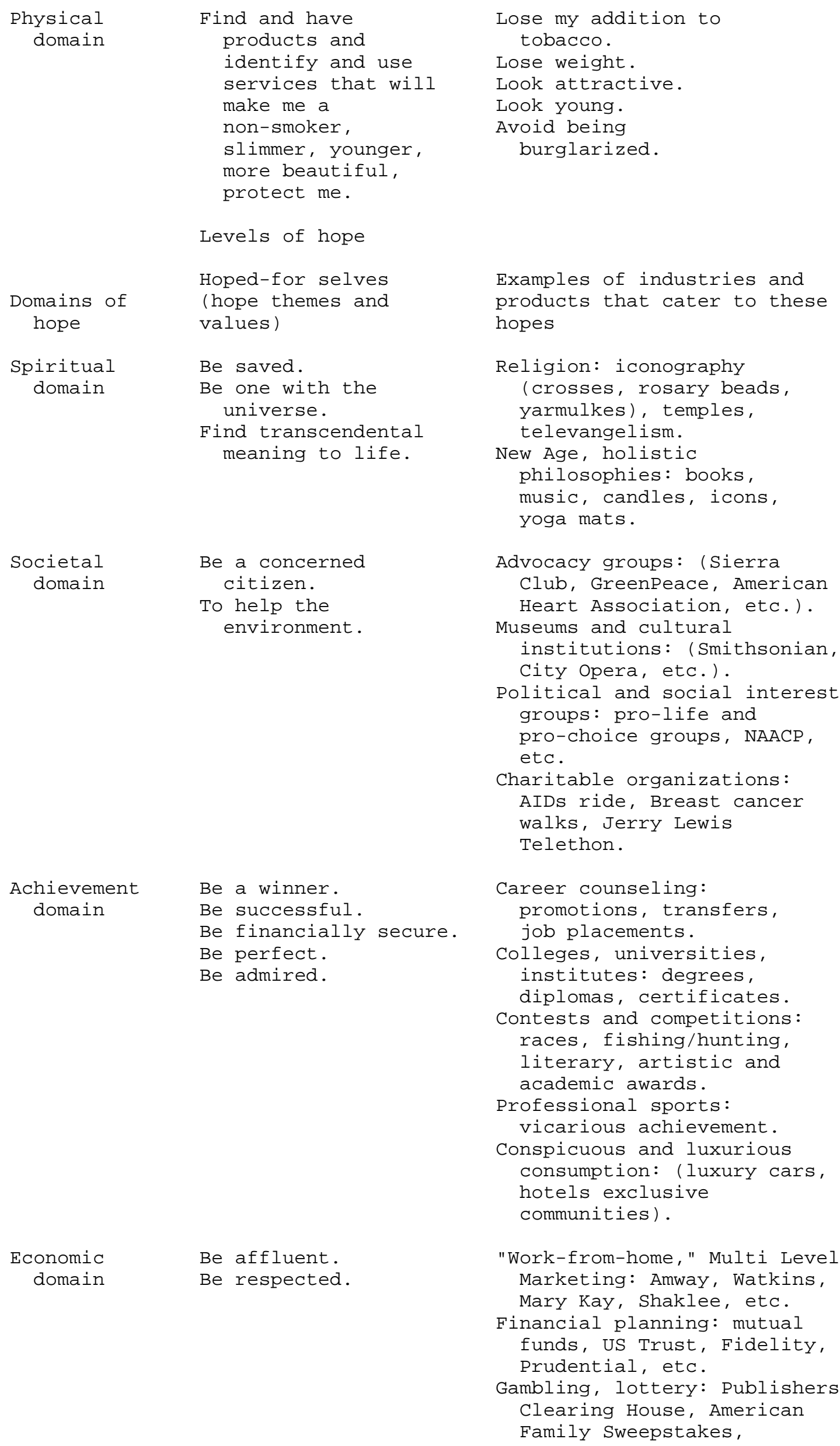

Find and have products and identify and use services that will make me a non-smoker, slimmer, younger, more beautiful, protect me.

Levels of hope

Hoped-for selves (hope themes and values)

Be saved.

Be one with the universe.

Find transcendental meaning to life.

Be a concerned citizen.

To help the environment.

Be successful.

Be financially secure.

Be perfect.

Be admired.

Examples of industries and products that cater to these hopes

Advocacy groups: (Sierra Club, GreenPeace, American Heart Association, etc.) .

Museums and cultural institutions: (Smithsonian, City Opera, etc.).

Political and social interest groups: pro-life and pro-choice groups, NAACP, etc.

Charitable organizations: AIDs ride, Breast cancer walks, Jerry Lewis Telethon.

Career counseling: promotions, transfers, job placements.

Colleges, universities, institutes: degrees, diplomas, certificates.

Contests and competitions: races, fishing/hunting, literary, artistic and academic awards.

Professional sports: vicarious achievement.

Conspicuous and luxurious consumption: (luxury cars, hotels exclusive communities).

"Work-from-home," Multi Level Marketing: Amway, Watkins, Mary Kay, Shaklee, etc.

Financial planning: mutual funds, US Trust, Fidelity, Prudential, etc.

Gambling, lottery: Publishers Clearing House, American Family Sweepstakes, 
casinos.

$\begin{array}{cl}\text { Interpersonal } & \text { Be a better parent. } \\ \text { domain } & \text { Be a better partner. } \\ & \text { Be a better friend. } \\ & \text { Be a good son/ } \\ & \text { daughter. }\end{array}$

Personality/ emotional domain

Physical domain

Be better adjusted.
Dating: personal ads, dating services (Model Quality Introductions, Elite Connections).

Self-help publishing: "Become a Better Parent," "Handbook for Living," etc.

Psychotherapy and counseling Religion, New Age, Eastern philosophies (see above).

Travel and tourism: romantic getaways, cruises, restaurants and spas, etc.

Gifts: Hallmark, etc.

Charitable foundations: Rotary, Lions, Red Cross, etc. Self-help publishing: over 21,000 titles listed in Amazon.com. "Seven Steps to ...."

Psychotherapy and counseling

Medicine and supplements: Prozac, Paxil, Zoloft, Effexor, SAMe, ginseng, etc.

Religion, New Age, Eastern philosophies: (see above).

Beauty: surgery (abdominoplasty, facelifts, eylid lifts, chin/cheek implants, rhinoplasty).

Exercise: gyms, home equipment, videos, magazines, TV shows.

Dieting: drugs, herbs, supplements (ephedra, Xenadrine, etc.), low-calorie foods.

Alternative medicine: homeopathy, shark cartilage, magnetic therapy (shoes, bracelets). Supplements: St. John's wort, kava-kava, ginseng, " natural artesian water," 


\section{Consumer relevant consequences of hope}

The concept of hope may be relevant to a number of consumer behavior outcomes. Given length constraints, however, we focus on only four. Biased processing and self-deception and risk taking behavior are examined as they represent novel and interesting outcomes not studied extensively by consumer researchers. Product satisfaction is studied because hope makes interesting predictions within the context of available theories. Life satisfaction and materialism are examined as they have important social policy implications. Propositions derived from

this discussion are presented in Table 1.3.

3.1 Biased Processing and Self-Deception Averill et al. (1990) identified eight categories that reflect the ways in which people think about and experience hope. Of the eight, one stands out as irrefutably negative: hope is deception. This notion is revealed by maxims, metaphors, and folk sayings such as 'Hope is the only liar who never loses his reputation for veracity;" 'hope is a charlatan who always defrauds us;" 'hope is a traitor of the mind; under color of friendship, it robs us of resolution." Likewise, Belk (1996) writes, "It is through hope and its accompanying suspension of cynicism and disbelief that we create that excited, if ultimately illusory state of anticipatory desire that sustains and nourishes us" (pg. 102; emphasis added). The comforting power of hope may thus make consumers susceptible to biased processing and self-deception (MacInnis and de Mello, 2005).

While empirical research linking hope to biased processing and self-deception is lacking, a number of persuasion models acknowledge that individuals are capable of processing information in a biased way, leading to conditions of self-deception (e.g., Petty and Cacioppo, 1986, Chaiken et al., 1989, Eagly and Chaiken, 1993). Individuals who engage in biased processing might, for example, ignore information inconsistent with attitudes, counter-argue attitude inconsistent information, and/or use heuristics that allow retention of the original attitude.

While individuals are motivated to evaluate available information in a self-serving manner they still wish to maintain an 'illusion of objectivity." That is, they will attempt to be rational and to 'construct a justification of their desired conclusion that would persuade a dispassionate observer" (Kunda, 1990). The marketing literature has also addressed the issue of biased processing and self-deception to a limited extent (e.g., Jain and Maheswaran, 2000, Langenderfer and Shimp, 2001, Agrawal and Maheswaran, 2005).

Research to date acknowledges that consumers engage in biased processing so as to retain entrenched, strongly held attitudes. However, consumers may also engage in biased processing so as to enhance beliefs that the hoped for outcome is possible or that the product is instrumental to its achievement (de Mello and MacInnis, 2005, MacInnis and de Mello, 2005). Hence under conditions where goal congruent outcomes are viewed as impossible, consumers may distort information to allow for the possibility of the goal congruent outcome. In other words, consumers engage in self-deception by seeing what they want to see. Shea (1981) also notes that hope expands flexibility, allowing reframing of events or conflict. Especially in the face of frustration, anxiety or despair of an unmet end perhaps, unattainable--goal, we seek solace in the comforting arms of hope, where we find safety, security, and "helter in life" (Kast, 1991). Studies in the health and psychology literatures support this effect (Lazarus 1991, 1999a, 1999b).

For example, Korner (1970) states that hope's key purpose is "the avoidance of despair," and its secondary function is 'permitting the individual psychologically to bypass ongoing unpleasant or stressful situations" (pg. 134). He adds, 'Hope allows partial fulfillment of unmet needs under the guise that it may one day be true." Since hope is linked with coping and is a mechanism against despair, individuals may cope with goal incongruent outcomes by engaging in biased processing that makes hoped for outcomes appear possible. 


\subsubsection{How Does Hope Affect Biased Processing?}

If hope affects biased processing, it may do so by initiating one or more of the processes characteristic of biased processing (Mele, 1997). First is negative misinterpretation. Yearning for a goal congruent outcome may lead consumers to misinterpret evidence against a goal congruent outcome that would normally be recognized as disconfirming. For example, lack of FDA backing to the claims of alternative medicines may be discounted on the basis that 'current scientific knowledge is not prepared to handle alternative or ancient ways of healing." Another process is positive misinterpretation. Here, consumers may interpret as supportive of the possibility of a goal congruent outcome data they would normally catalog as unsupportive. For example, a dating-service customer may attribute the failure of the matchmaker to introduce him to numerous potential mates to the firm's zeal to End the 'perfect" one. By selective focusing/attending, consumers yearning for a goal congruent outcome (e.g., weight loss) may to fail to attend to evidence against the outcome (e.g., the scale reads the same weight day after day) and focus attention on data supporting it (clothes 'feel a little looser)." Engaging in selective evidence-gathering, yearning for a goal congruent outcome (e.g., relaxation and harmonious states through aromatherapy) may overlook easily obtained disconfirming evidence (e.g., an expose on the untrue benefits of aromatherapy on the cover of Newsweek), and instead search for more elusive corroborating evidence (e.g., an article on the advantages of this practice appearing in New Age Magazine).

Processing can also be biased by the misinterpretation of incomplete and unrepresentative data. For instance, a consumer who hopes for a cure for cancer may be convinced that it is possible to cure it with positive thinking because he knows "somebody who whipped the Big C after practicing mental imagery" (Gilovich, 1991). Consumers may also 'rewrite" their histories of success and failure by to convincing themselves that the hoped for outcome is still possible and scrutinizing and explaining away their failures. Gilovich (1983) reports that gamblers in fact often rewrite their losses, counting some as 'near wins." The false consensus effect (Ross et al., 1977)--the tendency for an individual's beliefs to bias his/her estimates of how widely such beliefs are shared by others--is another source of self-deception that can be affected by hope. Consumers who hope to End fulfillment or health in New Age practices may exaggerate the degree to which their peers adhere to such a system of beliefs.

\subsubsection{Supporting Evidence}

Evidence supporting the link between hope and biased processing comes from the mood literature. As a positive emotion, hope may create a positive mood. Schaller and Cialdini (1990) found that interpretation of ambiguous material can be biased, being evaluated more favorably by individuals in a positive mood. More favorable information is retrieved from memory under a positive mood (Isen, 1987). Mood can be used as information to generate attitudes about objects. When individuals attribute their good mood to thinking about the attitude object, they tend to express more favorable attitudes about the target (Schwartz, 1990). Mood also tends to bias the perceived likelihood of uncertain events, with positive events appearing more likely during a good mood (Forgas et al., 1984). Finally, Kahn and Isen (1993) find that positive effect increases credibility that a product designed to reduce negative health effects will be successful. In sum, as a positive emotion, mood may bias processing in ways amenable to self-deception.

Other evidence for the potential link between hope and biased processing comes from the attitude literature. Chaiken et al. (1989) suggest that biased processing is likely when the individuals are ego-involved with an issue, as might be the case when an outcome is not only goal relevant but also associated with strong desire and viewed as important. These factors precipitate intense yearning and hope. In a related vein, Alcock (1995) states, 'When we are yearning most, when we are in the greatest need, we are even more vulnerable to fallacious beliefs that can serve to satisfy those yearnings."

Biased processing and self-deception may lead to some serious consequences, including spending money and adhering psychologically to outcomes that will not come to fruition. On the other hand, it is not clear that self-deception is always bad. Some suggest that self-deception has evolutionary/ adaptive purposes Heilmann 
(1997). Research has shown that people with low levels of self-deception have higher levels of depression (Taylor et al., 2000) and other psychopathologies (Heilmann, 1997). Lester (2000) argues that beliefs are resistant to change because they are designed to enhance our ability to survive. Perhaps the fact that hope springs eternal arises from its use as a coping mechanism to help survival in the bleakest of times.

While the effects of hope on biased processing and self-deception remain unexplored, its potential effects may be both wide-reaching and mixed in effects on consumer well-being, ranging from positive coping during times of adversity to minor nuisances (disappointment, small sums of misspent money) and from realized self-delusion to tragic outcomes (improper medication, injury, and death) from failure to encode and process potentially negative outcomes and hypervigilant actions to achieve it.

\subsection{Risk-Taking Behavior}

In addition to its potential effects on biased processing (or perhaps because of it), great yearning for a goal congruent uncertain outcome may motivate consumers to adopt paths to reach the outcome that entails a relatively high degree of risk (de Mello and MacInnis, 2005, MacInnis and de Mello, 2005, MacInnis et al., 2004). This might explain why consumers sometimes use radical means (e.g., plastic surgery, cranium binding) and means with limited testing (e.g., untested drugs, supplements) to attain yearned goal congruent outcomes (e.g., Schouten, 1991). A typical view on risk is its multidimensional nature, involving economic, social, psychological, or physical domains (MacInnis et al., 2004). Hence in any of these domains hope may be reflected in risk taking behaviors in any or all of these domains.

As evidence of the potential link between hope and risk taking behavior, Averill et al. (1990) found that respondents were likely to agree that they took added risks or stuck their neck out for things they hoped for. Prior research on consumers' risky and thrill seeking tendencies has focused on the nature of behaviors sought for their own right (Celsi et al., 1993). With hope, however, any enjoyment or experiential benefits are not endowed with consumers by risk taking. Rather risky paths are viewed as means for achieving the goal congruent outcome. Recently there have been attempts to link hope and risk taking (de Mello and MacInnis, 2005, MacInnis and de Mello, 2005). Below, we identify the four domains of hope as evidence of this potential relationship.

\subsubsection{Physical Domain}

According to Peiss (1998), women's hopes for beauty have historically relied on rather bizarre and radical means. For example, during the 1800s and early 1900s, covering the face with the warm urine of a small boy was prescribed as one of the remedies for reducing the appearance of freckles. The poisonous belladonna was advocated for sensual looking eyes and arsenic was adopted as a means of improving one's complexion. In the early 1900s, with hope of curing acne, consumers tried any number of odd methods ranging from eating three yeast cakes a day to undergoing carcinogenic X-ray treatments (Brumberg, 1998). Similarly drastic practices such as botulism toxin for wrinkles, silicone implants for a more attractive bosom, and surgery to attain a youthful appearance are in vogue today. Clearly practices such as these involve considerable physical and economic risk, but also psychological and social risk if not competently performed. The popular show 'Extreme Makeover" is one example of the lengths that consumers will go to in the hopes of achieving physical perfection (see also Woodman, 1982). The economic risks of such a strategy pale in comparison with the obvious physical risks involved. While it may appear illogical that consumers would elect to use consumption practices that deliberately involve risk, Schouten (1991) writes, 'People historically have undergone extreme discomfort, pain, and risk in order to conform to culturally prescribed standards of beauty" (pg. 413). Also in the physical domain, those with failing health are willing to take untested medications, therapies with no scientific backing, and controversial yet expensive methods of alternative healing.

\subsubsection{Interpersonal Domain}


Hope for the continuation of interpersonal relationships may motivate a number of risky behaviors. For example, teens' risk taking behaviors like underage smoking, drinking, drug use, shoplifting, and unprotected sex appears to stem from the hope to be cool, to ft in, and be liked (Chaffray and Schneider, 2000, Rose et al., 1992). The media commonly reports stories of family members who undergo serious medical operations (kidney, lung, bone marrow transplants) and risk their own lives in the hopes of saving the life of a beloved family member. Also in the interpersonal domain, childless couples who desperately hope for children are willing to undergo expensive and potentially dangerous physical procedures in order to become pregnant.

\subsubsection{Economic Domain}

Hope in the economic domain may also lead to risk taking behavior. For example, consumers who hope to obtain fast money might gamble (Clotfelter and Cook, 1989). Hamilton (1978) indicated enormous risk taking behavior on the part of Americans, Asians, and Chileans in response to the California Gold Rush. Such individuals risked their lives, their families, their fortunes, and the ability to return to their homeland for the prospect of striking it rich. Though hope was not invoked as a cause of this risk-taking behavior, these effects are consistent with the notion that risky behaviors may be caused by hope.

\subsubsection{Achievement Domain}

Finally, evidence suggests that hope for achievement is linked with risk taking behavior. In the domain of managerial decision-making, Williams and Narendran (1999) found that risk-taking decisions are more likely to be made by managers with high needs for achievement.

While empirical research confirming a link between hope and risk-taking behavior is warranted, so too is research on why hope affects risk-taking behavior. It is quite possible that the same factors that explain biased processing and self-deception predispose consumers for risk taking behavior. Yearning may focus consumers' attention on the possibility that the goal congruent outcome will vs. will not occur, not the possibility that a goal incongruent outcome could occur in its place (see Figure 1.1; MacInnis and de Mello, 2005). Yearning may also create mood effects that affect the nature and extent of processing regarding potential risks. Perhaps yearning heightens selective attention, making consumers more likely to End and process information regarding alternative (and potentially risky) procedures to goal attainment. Perhaps thinking about the yearned for outcome makes outcomes seem possible, stimulating beliefs about the efficacy of adopting a risky path. Specifically, yearning and the positivity associated with hope may encourage elaborated imagery (MacInnis and Price, 1987) of a favorable, goal-congruent outcome rather than unfavorable outcomes (MacInnis and de Mello, 2005). Clearly research on both hope and risk taking and the mechanisms by which hope induces risk-taking behavior is important.

Importantly, risk-taking behavior and biased processing cannot be explained by other concepts such as involvement as Kunda (1990, 1987) suggests that the motivation to arrive at favored conclusions increases the implementation of strategies and the invocation of beliefs that result in the desired conclusion by both high and low involvement individuals.

\subsection{Product Satisfaction}

Consumers' satisfaction with products has important implications for marketers given that satisfaction influences consumers' repeat purchasing, negative or positive word of mouth, and complaining behavior. As such, a variety of antecedents and theoretical perspectives regarding factors that affect product satisfaction have been identified (Yi, 1990, Szymanski and Henard, 2001, Spreng et al., 1996, MacInnis and de Mello, 2005). For example, the performance perspective argues that satisfaction is quite simply a function of whether the product does or does not perform. The expectancy disconfirmation perspective suggests that actual performance levels are compared with expected performance levels. If the product performs worse than expected, a negative disconfirmation occurs and consumers are dissatisfied. If the product performs much better than expected, a positive disconfirmation occurs and consumers are highly satisfied (e.g., Oliver 
and DeSarbo, 1988). Equity theory suggests that satisfaction is based on the ratio of inputs to outputs (costs to benefits) the consumer receives from the product in comparison with a referent other (e.g., Fisk and Young, 1985). The emotions perspective purports that emotions like contentment, anger, or joy experienced during consumption can leave affective tags on the product's memory trace that are accessed in satisfaction evaluations (Westbrook and Oliver, 1991). Attribution theory (Folkes, 1984, 1988) proposes that whether consumers are dissatisfied from a failed product performance depends on whether they can blame the manufacturer for failed outcomes, or whether failed outcomes are attributed to their own actions. These perspectives are, for the most part, non-competing, and evidence for any or all can be found.

Syzmanski and Henard's (2001) meta-analysis of the satisfaction literature concluded that three antecedents studied in past research are the most significant predictors of post-consumption satisfaction (a) disconfirmed expectations between what the product delivered and prior expectations, (b) equity perceptions, and (c) consumption emotions (e.g., joy, happiness, anger, disappointment, surprise). They did not examine the attributional perspective, however. Since less than $40 \%$ of the variance in satisfaction judgments has been explained by the variables studied so far, they advocate identifying additional antecedents to satisfaction judgments.

Can hope lend insight to the literature on post-consumption satisfaction? We believe it can, and we posit that yearning and uncertainty play a fundamental role in product satisfaction judgments. Consider fist the effect of yearning. Intense hope is associated with intense yearning for the goal congruent outcome. Yearning may make consumers more sensitive to the potential benefits to be received from product consumption than the costs involved in obtaining them. Consumers who desperately hope to lose weight, cure health problems, or resolve relationships will often gladly bear whatever costs are necessary to resolve this fundamental current concern.

Next, consider the effect of the uncertainty component. With hope, uncertainty exists regarding the likelihood of attaining the goal congruent outcome. Consumers who are uncertain about the achievement of the goal congruent outcome may not have strong expectations that the outcome will occur, let alone that the product will serve as the means to achieve this outcome. These two predisposing factors likely have profound effects on product satisfaction. Below, we consider the impact of hope on satisfaction by examining how hope affects many of the previously identified antecedents to satisfaction (see also MacInnis and de Mello, 2005).

\subsubsection{When Hope is Intense and the Goal Congruent Outcome is Realized}

Consider fist a situation in which use of the product is instrumental in achieving the goal congruent outcome (e.g., by using the new cancer drug, the cancer is cured). In this case, consumers experience a positive disconfimation because the actual outcome was positive though the outcome was uncertain and expectations for product success modest. Second, because the yearned for outcome came to fruition, the benefits received are likely to be perceived as substantially greater than the costs entailed, leading to positive perceptions of equity. Third, because the hoped for outcome occurred when the outcome was uncertain, the consumer experiences positive emotions, feeling not only highly satisfied, but also joyful, happy and potentially relieved (if the goal congruent outcome could not be controlled) or proud (if it is due to personal efforts; Bagozzi et al. (1999) (see Table 1.1). Moreover, because yearning is intense, the emotions that stem from achievement of a yearned for outcome are intense. Emotions of joy, happiness and perhaps relief are intense emotions, certainly more intense than emotions such as contentment. van Dolen et al. (2001) found that the more intense the feelings of irritation, pleasure, and contentment, the greater impact the emotions had on customer satisfaction. Finally, because achievement of the outcome is uncertain, consumers may attribute its occurrence to the product, thinking that they themselves may not have been able to make the outcome happen without the product. Thus, when the product does achieve the goal congruent outcome the consumer will likely be extremely satisfied with the product, and hope may affect satisfaction by affecting multiple predictors of satisfaction identified in the literature.

\subsubsection{When Hope is Intense and the Goal Congruent Outcome is Not Realized}


Consider next a situation in which use of the product is not successful in achieving the goal congruent outcome. We argue that in this case, product dissatisfaction is not likely to be strong. First, because achievement of the outcome is uncertain and expectations for product success are low, the magnitude of the expectancy--disconfirmation may be small, rendering negative disconfirmation minimal. Second, while the consumers did not achieve what was hoped for, they may not perceive that they entailed substantial costs in trying (e.g., "What did they have to lose by trying?"). Hence perceptions of equity may not be negative. Third, because the outcome is uncertain, consumers may have already anticipated potential failure, which in turn should minimize negative emotions such as disappointment. Consumers may also displace or refocus their hope on other products they might get, protecting and hence maintaining future hope. While consumers may suffer disappointment, hope for future resolution of the goal congruent outcome is a coping mechanism that keeps truly adverse feelings at bay. At extreme, consumers may even fail to encode a product failure due to self-deception and biased processing. Taylor et al. (2000) have found evidence of such illusions of success and well-being. Perhaps this explains why consumers continue to use nutritional supplements, anti-aging creams and the like despite their negligible effects. Fourth, because a priori expectations were low, consumers might resolve feelings of dissatisfaction by suggesting that perhaps their expectations for success were too high in relation to what was realistic. Hence attributions of blame may focus on the consumer and his or her perceptions of unrealistic possibilities and expectations, not the product. For example, a consumer may think $\mathrm{V}$ course a diet pill cannot make you lose 30 pounds in 3 days, but I wanted to lose weight so badly, I was willing to give it a shot." All of these factors suggest that when hope is intense and the product fails to achieve the goal congruent outcome consumers may not be strongly dissatisfied with the product. While it may appear odd to think that actual product performance could be potentially unrelated to satisfaction, Szymanski and Henard's (2001) meta-analysis revealed that actual product/service performance was not a significant predictor of satisfaction. Hence, one can imagine situations in which a product fails to perform yet consumers fail to become dissatisfied.

\subsubsection{Implications}

The foregoing suggests that marketers generally benefit from enhancing consumers' hope (MacInnis and de Mello, 2005). Intense levels of hope will create deep levels of delight and consumer satisfaction if the product delivers a yearned for outcome. Delight may in turn affect the bottom line profitability by stimulating repeat buying and positive word of mouth. If the product does not deliver, disappointment may be mild, attributed to the self, defected to future products, or not encoded in the fist place. As such, consumers are less likely to complain and spread negative word of mouth, and may even be receptive to trying the product again when improvements suggest that the goal congruent outcome will be subsequently achieved.

\subsection{Life Satisfaction and Materialism}

Given the potential relationship of hope to product satisfaction and its benefits to marketers, one wonders about its effects on life satisfaction and perceptions of happiness, and hence its benefits to consumers. Earlier we suggested that perceived deficiencies stimulate hope through their effect on yearning. One wonders what happens when deficiencies fail to be resolved and hoped for outcomes are not achieved. While we have suggested earlier that when hope is intense such failures may not create profound product dissatisfaction, we still must ask, do they affect satisfaction with life?

\subsubsection{Life Satisfaction}

Empirically, researchers in psychology have found that unresolved discrepancies between the actual and hoped for self are associated with lower self-esteem (Higgins, 1987), and feelings of disappointment (Cantor et al., 1987, Campbell, 1987), dejection, and sadness (Higgins et al., 1986). Richins (1991) found that young women compare their bodies with that of ideal or hoped-for others (e.g., beautiful models in magazine ads), and that a discrepancy between the ideal other and the self makes them feel less physically attractive and less satisfied with their physical attractiveness. Sirgy et al. (1998; see also Pollay, 1986) suggest that unhappiness with one's standard of living and with life is triggered by television viewing, perhaps because consumers feel 
deficient in comparison with the idealized images shown on TV shows and in advertising. Admitting the ethical bind that surrounds the marketing of hope, Davidson (1998, pg. 6) writes, "Are we promoting too heavily the idea that happiness depends on having a more perfect, more youthful body? Are we trying to uncover another segment of "Vulnerable" customers: men and women so insecure about their physical appearance that they will pay hundreds and thousands of dollars for admittedly risky and quite likely short-term results?"

While the failure to achieve a hoped for outcome can result in negative feelings about the self and one's life, does it logically follow that achievement of a hoped for outcome yields positive feelings? On the one hand, the feelings of joy and happiness that follow achievement of a hoped for outcome should enhance self worth and feelings of satisfaction. On the other hand, such feelings may be ephemeral as the joy surrounding goal achievement soon gives way to new hopes, new goals, and new ideals. Consistent with this notion, Belk et al. (1997) found that when consumers thought about the feelings from obtaining a desired (and possibly hoped for) outcome, many noted negative feelings such as boredom, disappointment, and emptiness.

The above suggests that ironically dissatisfaction with self and life may arise both when hopes are not realized and when they are. Society provides a mechanism for resolving this dilemma though materialism (Belk, 1985). Materialism has even been described as a 'earning to consume" (Cushman, 1990). Richins (1995) writes, "When people are discontented--they look about themselves to determine how they can make themselves happier and how they can improve their lot.... The answer provided by advertising is 'more stuff."' (pg. 604).

\subsubsection{Materialism}

Campbell (1987) proposes that the most vivid feature of today's consumer society is insatiability for goods. The marketplace is also a context in which one can achieve when achievement in other contexts is not possible (Richins and Dawson, 1992, Richins and Rudmin, 1994, Richins, 1994). Belk (1984) writes that at the highest levels of materialism, 'possessions assume a central place in a person's life and are believed to provide the greatest sources of satisfaction and dissatisfaction" (pg. 291). Cushman (1990) argues that an 'empty self" is soothed in contemporary society by being filed up with gratifications like food and consumer products, though these gratifications offer little long term potential for true fulfillment. Fitzgerald (1979) further expounds, "There is always the problem of 'never enough." The objects of the pursuit do not satisfy within because they cannot.... The more one strives for "pleasure" or 'happiness" or "satisfaction"--the more the end eludes one." (pgs. 247-248). The linkage of hope with materialism is nowhere more apparent than in the ritualistic activity of contemporary holiday gift giving (Belk, 1989). Children sit in wait for gifts they hope to receive from Santa Claus while adults hope for gifts given by significant others.

\subsubsection{The Materialism/Life Satisfaction Cycle}

Unfortunately, rampant materialism provides little solace for those whose hopes are not satisfied (Sirgy et al., 1998, Belk, 1996). Materialistic consumers tend to have lower levels of satisfaction with various domains of life, including material comfort and their economic situation (Keng et al., 2000). Not only does consumption fail to provide long-term gratification, it entails entropy costs that deplete life energy (Csikszentmihalyi, 2000). An automatic response is further consumption, trading up to better and better consumer goods that will presumably provide life energy. McCracken (1990) echoes that once individuals take possession of objects previously tied to displaced future meanings, the meaning of the object is subject to empirical test, and the individual will likely realize that the product made them none the happier. Since consumption does not satisfy in the first place, repeated rounds in this cycle will likely lead to feelings of disappointment, emptiness, and dissatisfaction with life. As evidence of this potential, consumer researchers (e.g., Belk, 1985, Richins and Dawson, 1992) have found that materialistic consumers tend to feel less satisfied with their lives. A similar phenomenon exists when consumers have everything at their disposal money, goods. Such 
individuals are often dissatisfied, as their future seems bleak without displaced meanings to guide them. As McCracken (1990, pg. 113) writes, 'Never can they say, "if only I could have a rose-covered cottage, then...." There are no happiness or fulfillment contingencies in the lives of the very rich." 


\section{Are marketers purveyors of hope?}

If the marketplace is not a source of life happiness and satisfaction, one wonders to what extent marketers enhance dissatisfaction with life and ramp up materialism by stimulating hope. Charles Revson, founder and president of Revlon was famous for his claim, 'in the factory we make cosmetics. In the store we sell hope." This statement suggests two important facts: (1) consumers turn to the marketplace as a source of hope and (2) marketers are purveyors of hope who implicitly or explicitly use tactics to induce hope. Below, we deal with each issue in turn.

\subsection{The Marketplace as Source of Hope}

Table 2.1 and the above discussion suggests that consumers do indeed turn to the marketplace as a source of hope. We examine other evidence favoring this conclusion here.

Throughout time, hope has been linked with religion (Tiger, 1979, Rycroft, 1979). Unlike other life domains where the achievement of hope by one means that others fail to achieve what they hope for (e.g., wealth, recognition), there is room for everyone in Heaven. Hence, to the religiously faithful, fulfilling hope for today seems less important than hope for the everlasting joys experienced in the after-life. However, the secular world of consumption affords many opportunities for hope beyond the sacred and spiritual hope offered through religion. Hope is made available in explicit or implicit ways, encompassing a catalog of products and services designed to create hope for the attainment of goals in the life domains described in Table 2.1.

Indeed, Belk (1996) argues that our society has witnessed a transformation of the locus of hope -from religion and redemption to the marketplace and consumption. The religious experience of Christmas, for example, has moved from a spiritual practice focusing on the birth of a savior to a commercial enterprise focused on consumption and Santa Claus (Belk, 1987, 1989). Rather than spending the day set apart for worship, Sundays are just as often spent on trips to the mall where fantasies of new lives and better things are indulged.

Furthermore, there is a mixing of secular and sacred worlds in the marketplace. The idea of 'wealth as a sign of salvation," reminiscent of Weber's analysis of the Protestant ethic (1976, original pub. 1904) is evidence of this blurring. The blurring of lines between the religious/sacred and mundane/profane world is also evident in the rise of televangelism and the search for salvation through giving to pseudoreligious conglomerates and the selling of their wares (O'Guinn and Belk, 1989). Religious rituals like marriages performed by the children of God in the house of God are relegated to profane worlds like Las Vegas, witnessed by ordinary citizens in plastic chapels.

Moreover, consumption goods are often embodiments of both the world of the sacred and the profane. A good may signify not only a commodity product to be used in a secular world, but also a magical or spiritual object that suggests utopian possibilities (Belk, 1996).

\subsection{Marketers as Purveyors of Hope}

Rycroft (1979) suggests all societies tend to divide themselves into purveyors and recipients of hope. The recipients or consumers of hope are, as Rycroft describes, the "ordinary people," those of us who need to rid our lives of deficiencies, real or perceived, in any one or more of the dimensions mentioned in Table 2.1. Throughout history, the purveyors of hope have donned a variety of costumes. They are those "special people -priests, shamans, gurus, doctors, consultants, psychoanalysts whose esoteric training endows them with some sort of "mana" or charisma by the others and who may or may not themselves privately believe in the 
superior qualities attributed to them." (Rycroft, 1979, pg. 17) The last century has spawned an elite crowd of 'pseudo-purveyors" of hope: music and movie stars, sports heroes, and 'celebrities" who, in Daniel Boorstin's (1992) famed definition, are individuals known for their well-knownness, people whose appeal is primarily to persons devoid of their own self and who therefore over-identify with the heroes and cliques (Cushman, 1990).

That marketers are purveyors of hope is suggested through (1) their use of such celebrities and sports heroes in the marketing of products, (2) the numerous industries identified in Table 2.1 that cater to consumers' hopes in various life domains, and even (3) use of the word 'hope" in brand names. A number of self-help books and tapes include the word hope in their titles. BotanicLabs markets Spes--a mix of herbs that purportedly increases resistance to stress. Spes is the Latin word for hope. PC-Spes is a product designed to provide hope to those afflicted with prostate cancer. However, evidence that marketers are purveyors of hope is best revealed through the numerous tactics that seem apparently designed to induce hope.

\subsection{Tactics Designed to Enhance Hope}

Lazarus (1991) indicates, 'there is little research or theory on which to draw to understand the conditions under which hope appears" (p. 286). However, if hope is defined as a positive emotion that varies as a function of the degree of yearning for an uncertain, yet possible outcome, stimulating hope should be feasible by affecting one or both of these factors (MacInnis and de Mello, 2005, MacInnis et al., 2004). Below, we identify a number of marketing tactics that may induce hope by their effects on yearning and making an impossible outcome seem possible. Though these tactics in no way exhaust the inventory of possible hope inducing tactics, their enumeration reveals the myriad tools available in the marketer's toolkit. Table 1.3 develops testable propositions regarding these tactics.

\subsubsection{Tactics Designed to Affect Yearning}

As suggested in Table 1.3, some tactics may affect hope by intensifying yearning, either by stimulating desire, importance, or perceived deficiency.

Desire, and hence yearning and hope, should be enhanced through tactics that highlight the seductive nature of the goal congruent outcome, its relevance to dreams, and the fantastic states to which it can bring the consumer. This outcome is likely achieved through use of fantasy imagery (MacInnis and de Mello, 2005), perhaps through marketing communications. Considerable research in psychology, particularly in the area of sexual arousal, links positive fantasies with desire (e.g., Oettingen et al., 2001, Przybyla et al., 1983). Belk (1996) describes how places like Las Vegas and shopping malls have become fantasy-like, not only displaying an alluring and dazzling array of consumption goods and activities, but fantasy characters, themes, and surroundings that suggest a departure from the ordinary, the possibility of better, and mo re fantastic life experiences. Baudrillard (1983) has extensively studied these "hyperreal" places, calling them "simulacra."

The hype surrounding the value of lottery prizes provides rich fantasy material for consumers. Media stories highlighting winners who share how their big win will transform their lives likely stimulate consumers' fantasies about what they would do with a winning jackpot. Clofteler and Cook's (1989) studies of the lottery also show a strong relationship between the value of the jackpot and the number of lottery tickets sold. While the number of tickets sold decreases the individual's odds of winning, it is possible that information regarding the increasing size of the prize stimulates desire for the jackpot, perhaps by stimulating self-induced fantasies of the value of a win. The greater these desires, the more likely the consumer is to buy a ticket. Even game titles (e.g., Fantasy Five) include the word fantasy.

Fantasy is not restricted to gambling. The dating industry induces fantasies of finding a "soul mate," emphasizing how much better life is when shared with the right partner (i.e., "Those sunsets are much more wonderful when you have someone to share them with"). Stores, catalogs, and ads, sometimes, promote fantasy environments in which product consumption is linked with such hoped for outcomes as culinary 
delights (Williams- Sonoma), romantic encounters (Victoria's Secret), and play (Disney). The New Age industry promises fulfillment of fantasies. A recent issue featured articles such as 'bight lessons from everyday experts will help you attain your dream." Advertising not only provides rich material for fantasies--it sometimes links the product to the fantasies of consumers in the ad. Such is the case, for example with Reebok's recent commercial depicting a young man fantasizing about being Allen Iverson; a fantasy presumably shared by many young men.

Belk et al. (2003) suggest that a characteristic of desire is its approach/avoidance potential. Desired outcomes may be hedonistic and self-centered, creating temporary gratification at the cost of negative feelings down the road. However, consider how much more yearning would be stimulated if the approach component could be realized without the accompanying avoidance component. Hence in addition to fantasies, a second tactic designed to induce yearning and hope is to suggest that the product resolves an approach/ avoidance conflict (MacInnis and de Mello, 2005). Consider, for example, the approach/avoidance conflict caused by typical diet foods (low in calories or fat but bad in taste). However, what if the product were positioned as achieving the approach (goal congruent) outcome (low calories/fat) without simultaneously creating the avoidance (goal incongruent) outcome (bad taste)? A number of diet ads and packages, for example, claim that brands allow consumers to lose weight while eating as they normally would. Sunless tanning products claim to provide a natural streak-free tan without exposure to the dangers of the sun and radiation. Some skin care systems claim to provide outcomes that are as good as what could be provided by a dermatologist, without expensive dermatology bills. Most, if not all, abdominal machines guarantee great abs without effort. Infomercials promote multi-level marketing schemes that promise high income without leaving home. Dating services provide ways to meet people without having to go to bars.

Several other marketing tactics appear to affect hope by operating on the importance dimension of yearning. To the extent that products and services not only attain or solve lower order goals, but also are instrumental to the attainment of higher order goals, they should be perceived as more valuable and important and hence generate more yearning and hope (Austin and Vancouver, 1996, MacInnis and de Mello, 2005). Diet and exercise ads often claim that not only did the product help the protagonist lose weight, it has also helped her have a more romantic and physical relationship with her husband, thereby enabling social approval and love.

Finally yearning and hope can also be enhanced by highlighting deficiencies. Deficiencies are sometimes created through social comparisons (e.g., see Richins, 1995). Marketing tactics frequently associate their product with lifestyles that can be achieved by few and with members of aspirational reference groups whose popularity, status, or notoriety is well beyond that achieved by the average consumer (e.g., Richins, 1991). This concept goes hand-in-hand with Weber's suggestion that material success and achievement are signs of "salvation" and being among the 'chosen ones" (1976). Lottery ads that compare the glamorous life achieved by the few who have gotten lucky" enhances hope of achieving a similar outcome (Clotfelter and Cook, 1989). Weight loss and beauty ads and packages feature ultra slim and superfit models that epitomize beauty, yet whose beauty can be replicated by few. Jewelry ads and displays show diamonds and gems completely beyond the economic means of most consumers. Athletic equipment ads and packages feature athletes whose prowess is both rare and admired. Dating ads and catalogs for sexual products create the impression of fiery passion and bliss that rarely characterize longstanding relationships. Religions promote deities and prophets as the ideal conception of humankind and create an ideal image in which we should follow. The media and advertising arenas are rich sources of imagery regarding ideal or utopian worlds (Hirschman, 1988, McCracken, 1990, Richins, 1991) as Hollywood and Madison Avenue often portray ideal images of society or a particular social group. In addition to deficiencies created by the exposure to ideal images through social comparisons, yearning can also be enhanced by comparing the current self to an ideal past self or an ideal future self (MacInnis and de Mello, 2005). Advertisements can affect self-deficiencies by inducing consumers to make comparisons between themselves now and an ideal past.

While ideal images can make individuals feel deficient by comparison, focusing on deficiency directly (without any explicit comparison to an ideal) is itself a powerful tactic for enhancing perceived deficiency. Consumers are made to feel deficient at the gym when trainers weigh, measure, and provide body fat tests. 
The dating industry stimulates yearning by pointing at the deficiency in love in the person's life. While it might not be necessary to increase yearning for such a vital goal as health, it is nevertheless possible to exacerbate it by bringing into awareness a potential deficiency in health (i.e., "if you are over 40-years old and have family history of heart disease ..."). Multi-level marketing communications suggest how alignment with the company can help consumers get over the drone or working for others and instead feel fulfilled. Even the affluent can be made to feel deficient. An ad for U.S. Trust warns the rich 'money is not the end of the worry, it is the beginning." Indeed, some advertisements claim that the individual is not only deficient in some quality, but is deficient in basic and fundamental ways that reflect his or her character. Davidson (1998), for example, notes that ads for hair growth products link baldness with a deficiency of not only hair, but also personality (e.g., diminishing self-esteem), emotional strength (e.g., depression), and low quality of life. In a recent article on Reebok's advertising the ad's creative director noted, 'The gist of this spot for the fan is, sure, you can wear his shoes, but can you fill them?" (Thomaselli, 2001).

\subsubsection{Tactics Designed to Make the Impossible Seem Possible}

While the above tactics may evoke hope through yearning, others may work by making the impossible seem possible. Achieving goals is impossible if one does not know how. Accordingly, perceptions that goals once impossible to achieve are actually possible should be enhanced when one reveals secrets, or previously unknown tricks, tips, steps, and solutions to achieving them (MacInnis and de Mello, 2005, MacInnis et al., 2004). A number of industries suggest that goal congruent outcomes are easily achieved by virtue of knowledge of "'secrets," "tips," or "tricks" to make them happen. Consider, for example, the titles of the following books: Secret Sexual Positions; Secrets to Making Great Pictures; The Millionaire Next Door: Surprising Secrets of America's Wealthy; and 92 Little Tricks for Big Success in Business and Personal Relationships. A cover of Cosmopolitan indicates that novel tips inside help the reader make her man her 'love slave." The same cover indicates that the reader can learn five 'spotlight grabbing tricks" tonight to be the girl everyone is dying to know. She can also learn 21 secret ways to tempt, tease, and intrigue him into only having eyes for her. Promises of possibilities are also heightened by marketplace mechanisms that imply that difficult goals can be achieved by following a few simple steps. Consider, for example, the self-help books titled Ten Steps to Reversing Aging; Nine Steps to Financial Freedom; and Seven Steps to a Pain Free Life.

Achieving what was viewed as impossible also seems possible when we witness others whose success has been achieved. We have long known that use of similar others in marketing communications creates identification with a viewer, enhances an ad's or salesperson's perceived self-relevance and makes appeals more credible (e.g., Eagly et al., 1978). However, such endorsements and testimonials may also evoke hope since similar others are perceived as diagnostic of one's own capabilities (Bandura, 1997). A model or salesperson who communicates that she has faced a seemingly insurmountable goal (e.g., a similar battle with weight loss, trying all kinds of diet products, having no success) and yet has had success with a particular product or service, may open up perceived possibilities of success and hope for attaining the goal congruent outcome described by the endorser.

Use of this tactic is common in a variety of marketing contexts. The weekly announcement of new lottery winners serves as evidence that winning is possible. News coverage of big winners leads to an inevitable logic - why not me next time? The weight loss and exercise industries affect perceptions of possibilities by the use of testimonials accompanied by 'before and after" pictures. The cosmetics and cosmetology industry shows 'makeovers" of average people made beautiful by the cosmetologist's hand. Televangelism often highlights the experiences of others who claim to have come to "see the light" from their religious experience.

Possibilities may also be enhanced by aspiration groups, as comparisons with idealized people change consumers' reference points for what is likely as long as the ideal other falls within the gone of possibility" 
(Richins, 1995). Thus, the use of celebrities, models, and sports players who are more desirable than the current self, but not so perfect as to reflect unachievable outcomes, may affect hope by altering perceptions of what is possible. 


\title{
5 How can hope be measured?
}

\author{
Foundations and Trends in Marketing
}

The measurement of hope is critical to future research on the subject. Unfortunately, just as the concept has received relatively little attention from researchers in various disciplines, so too has its measurement. A complete measure development and validation exercise is beyond the scope of this paper as it represents a paper in and of itself (e.g., Richins, 1997). As such our focus is on developing a preliminary set of hope measures that can be validated in future research. We compare our measures to existing measures and identify considerations involved in their use.

\subsection{Formative vs. Reflective Measures of Hope}

Two approaches to measurement can be identified: reflective and formative approaches. Most common is the development of scales comprised of a set of items designed to indicate or reflect the construct of interest. Researchers following the reflective approach to measurement follow the procedures for measure development advocated by Churchill (1979) and rooted in classical test theory. Examples of reflective measures of hope are scales that include such items as 'My hope for this outcome has never been higher," "I do not hope this outcome will happen" (reverse scored), and others shown in Table 5.1. Assessing hope using a reflective scale would be an improvement over current methods of measuring hope, which typically use a single item measure (e.g., at the moment, I feel hope) (e.g., Frijda et al., 1989, Roseman, 1991, Roseman et al., 1990, 1994, Smith et al., 1993).

A second approach involves the use of formative measures, indicators that combine to determine a specify construct (Bagozzi, 1982, Bagozzi and Fornell, 1982, Diamantopoulos and Winklhofer, 2001). For example, education, occupation, income, and neighborhood are combined as an index of socioeconomic status.

Diamantopoulos and Winklhofer (2001) note that while use of formative measures is common in other disciplines such as economics, their use is rare in marketing. Formative measures are appropriate when a concept is said to be a function of or defined by its measures (Bagozzi and Fornell, 1982). Such appears to be the case with hope, which is defined by the dimensions of yearning for a goal congruent outcome and uncertainty/possibility regarding the future (see Table 1.1 and the conceptual definition of hope). It is also consistent with appraisal theory which regards hope as evoked by situations appraised as goal congruent and yearned and also uncertain yet possible.

Diamantopoulos and Winklhofer (2001) argue that an important consideration in the development of an index based on formative indicators is indicator specification: one must be certain that each of the relevant factors affecting the construct has been identified, as omission of any one would lead to a misspecification of the construct itself. This idea is consistent with Rycroft (1979) who writes, "Hope is something that only exists contingently" (pg. 3). Given the considerable time already devoted to describing the hope construct and its constituent elements, we assume that our specification is fairly accurate. As Table 1.1 suggests, omitting any of these variable that constitute hope would reveal different emotions, not hope.

Diamantopoulos and Winklhofer (2001) also note that unlike reflective measures, an assessment of internal consistency of the items is inappropriate for formative measures, as the items should not "hang together" in forming a scale. Unlike reflective scales where high correlations among the various indicators indicate internal consistency reliability, high correlations among indicators of formative measures are undesirable since the formative approach to measurement is based on a multiple regression model where high correlations between the various indicators make it difficult to assess the relative impact of each indicator on the latent variable [eta] (see Diamantopoulos and Winklhofer, 2001). As suggested in Table 1.1, while yearning is embedded within goal congruence and uncertainty regarding a possible outcome is embedded within a future time perspective, yearning and uncertainty are not correlated and in fact are quite independent. Hence multicolinearity does not appear to be an issue. 
Bollen and Lennox (1991) suggest that the following form indicates specification of a formative measure:

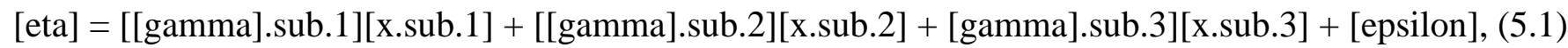

Where [[gamma].sub.i] is a parameter that reflects the contribution of [x.sub.1] to the latent variable [eta] and $\mathrm{e}$ is the disturbance term. Using a formative measurement approach then, hope might be characterized by the following:

Hope $=[$ gamma $]$. sub.1] yearning for goal congruent outcome $+[$ gamma $]$. sub.2] uncertainty/possibility about the future + [epsilon]. (5.2)

However, because Table 1.1 shows that hope is the joint product of yearning for a goal congruent outcome and uncertainty over the future state, we propose the form of the model is better characterized as a Cobb-Douglas type function, (1) with hope assumed to be a multiplicative function of several constructs. That function would suggest that hope is specified as

Hope = yearning [[gamma].sub.1]* uncertainty/possibility [[gamma].sub.2]* [epsilon], (5.3)

where hope represents the interaction between yearning for the goal congruent outcome and uncertainty/possibility regarding its future occurrence, and [[gamma].sub.1] and [[gamma].sub.2] represent weights that account for potentially differential effects of yearning and uncertainty/possibility in their impact on hope. One could estimate this model by transforming the equation, taking the natural log of both sides. Such a transformation would yield:

$\ln ($ Hope $)=[$ gamma $] . s u b .1] \ln ($ yearning $)+[$ [gamma $] . s u b .2] \ln ($ uncertainty/possibility $)+[$ epsilon $] .(5.4)$

\subsection{Operationalizing Yearning and Uncertainty/ Possibility}

Of course, this measurement approach assumes the existence of measures of yearning for the goal congruent outcome and uncertainty/ possibility of a future state. One might conceptualize yearning and uncertainty as single item indicators (e.g., I truly yearn for the existence of this outcome; I am not sure whether this outcome will happen). However, in this approach, each hope element is itself indicated by a single item measure. An alternative approach would assume that the indicators of hope are themselves indicated by a set of items measured as reflective scales. A preliminary set of items indicating each predictor of yearning, as well as a reflective scale measuring uncertainty/possibility is shown in Table 5.1. (2)

\subsection{Empirical Issues}

Several empirical research issues can be raised with respect to this scale. One concerns the appropriate functional form of the hope model. From a theoretical standpoint, we expect that the multiplicative Cobb-Douglas type formulation best characterizes the measurement of hope, however, this formulation should be tested against a baseline model in which the various indicators of hope are additive. A second issue concerns the formulation of the formative indicators of yearning: desire, importance, and deficiency. It is possible that the following form best indicates yearning:

Yearning $=[$ gamma $]$. sub.1] desire $+[$ [gamma $]$. sub.2] importance $+[$ [gamma $]$. sub.3 $]$ deficiency $+[$ epsilon $]$. $(5.5)$

Here desire, importance, and deficiency contribute additively and independently to yearning. However, it is also possible that yearning is a function of the interactive effects of desire, importance, and deficiency and hence is greatest when reflecting desirable and important outcomes that also entail deficiency. Hence, hope for winning the lottery is greatest among those who are truly deficient in cash, who also need the money for important reasons like saving their lives (e.g., to pay off loan sharks), and who also fantasize and desire a life 
of limited financial worry. Hence, we believe that the functional form that best characterizes the relationship between the three and yearning is:

Yearning $=$ desire [[gamma].sub.1] $*$ importance [[gamma].sub.2] $*$ deficiency [[gamma].sub.3] $*$ [epsilon]. (5.6)

However, the most appropriate functional form is an empirical issue.

A third issue concerns scale validity. Bagozzi (1994) suggests that the best way to assess the validity of a scale comprised of formative indicators is to see how well it relates to other variables in a nomological network. Hence, validation of this measure can occur in several ways. First, it is possible to develop a reflective measure of hope as specified in the left-hand column of Table 5.1 and determine the percentage of variance in these items explained by the interaction between yearning for the goal congruent outcome and uncertainty over its future occurrence as indicated by the items in the right-hand column of Table 5.1. Alternatively, or in addition, validity can be assessed by evaluating the linkage of both hope measures to other constructs like biased processing, satisfaction, materialism and risk-taking behavior in a nomological network.

\subsection{Comparison to Existing Measures of Hope}

Despite a sincere attempt at a thorough review of the literature, the authors were unable to uncover any measures of hope beyond the use of single item measures (e.g., right now, I hope that ...). The hope scales that were identified appear to tap hopefulness or optimism, not hope.

\subsubsection{Snyder's Hope Scale}

Snyder et al. (1996) developed a 6 item scale that appears to measure hopefulness. The measure has adequate psychometric properties (reliability, construct validity, discriminant validity, convergent validity). In the State Hope Scale, respondents respond to statements that reflect pathways (e.g., If I should End myself in a jam, I could think of many ways to get out of it; There are lots of ways around any problem that I am facing now) and agency (e.g., Right now, I see myself as being pretty successful; At this time, I am meeting the goals I have set for myself). The more pathways an individual identifies and the more s/he feels personally efficacious at achieving the goal, the more hopeful s/he is that the goal congruent outcome can be achieved. This measure does not capture hope as it (1) ignores yearning, and (2) focuses on perceived success at achieving previously set goals as opposed to the uncertainty regarding the achievement of a specific future goal congruent outcome.

\subsubsection{The Miller Hope Scale}

Based on their definition of hope as 'pan anticipation of the future which is good," Miller and Powers (1988) developed the 40-item Miller Hope scale. Items from their scale loaded on three factors. The fist, labeled satisfaction with self, others, and life included such items as 'I am currently satisfied with my life," 'life has meaning," 'I am valued for what I am," and 'I am at peace with myself." The second, labeled avoidance of hope threats, included such items as 'I feel preoccupied with troubles," 'I feel overwhelmed," and 'I feel trapped." The final factor was labeled anticipation of a future and included such items as 'I value freedom," 'I look forward to enjoyable things," and 'I spend time planning for the future." Unfortunately these factors do not correspond with any general definition of hope and the factor loadings are quite low. Moreover, the scale seems to tap a positive orientation toward life as opposed to the extent to which one yearns for a specific goal congruent outcome. (3)

\subsubsection{The Herth Hope Index}

Herth (1992) developed a scale designed to measure the extent of hope felt by patients in clinical medical 
settings. The index is a shortened version of a longer 30-item index and is comprised of 12 Likert scored items reflecting one of three factors thought to underlie hope: (1) an inner sense of temporality and future (e.g., ' 2 believe that each day has potential" and 'Y have specific possible short, immediate, or long range goals") and (2) inner positive readiness and expectancy (e.g., "I see a light at the end of the tunnel" and 'Y have a sense of direction"), and (3) interconnectedness with self and others (e.g., "I have faith that gives me comfort" and 'Y am able to give and receive caring/love"). A study of 172 acutely ill patients using this scale found high correlations between this scale and the longer Hearth hope scale, as well as high correlations with the Existential Well Being Scale and negative correlations with the Beck Hopelessness scale. The items on this scale also seem to tap hopefulness as opposed to hope.

\subsubsection{Dispositional Hope Scales}

A number of other hope scales tap the inherent traits of individuals inclined to be hopeful or optimistic across time and situation (e.g., Snyder et al., 1991, Nunn et al., 1996). However, these scales are not relevant to the measurement of hope as hope is an emotion that describes the psychological state of an individual at a point in time. These scales assess dispositional hopefulness.

(1) The traditional Cobb-Douglas production function assumes that output is the joint function of capital, land, and labor. It is represented as production = capital [[gamma].sub.1] land [[gamma].sub.2] * labor [[gamma].sub.3]* [epsilon].

(2) We argue that yearning is embedded within goal congruence and that possibility/uncertainty is embedded within future orientation. However, one might argue that inclusion of items that measure these constructs is necessary. Such items might be measured as follows: Indicators of goal congruence: (1) This is a good outcome, (2) Having this outcome occur is bad (r), (3) having this outcome happen is generally consistent with the things that I would like to see happen to me; Indicators of future orientation: (1) I am waiting for this outcome to happen, (2) This outcome has already occurred (r), (3) This outcome is occurring at exactly this moment (r). With this formulation, hope would be measured by hope = yearning [[gamma].sub.1] * goal congruence [[gamma].sub.2] * future orientation [[gamma].sub.3] uncertainty/possibility [[gamma].sub.4]* [epsilon].

(3) Another hope scale has been developed by Obayuwana et al. (1982). However, the scale and its items are not described, making it impossible to discern what it measures.

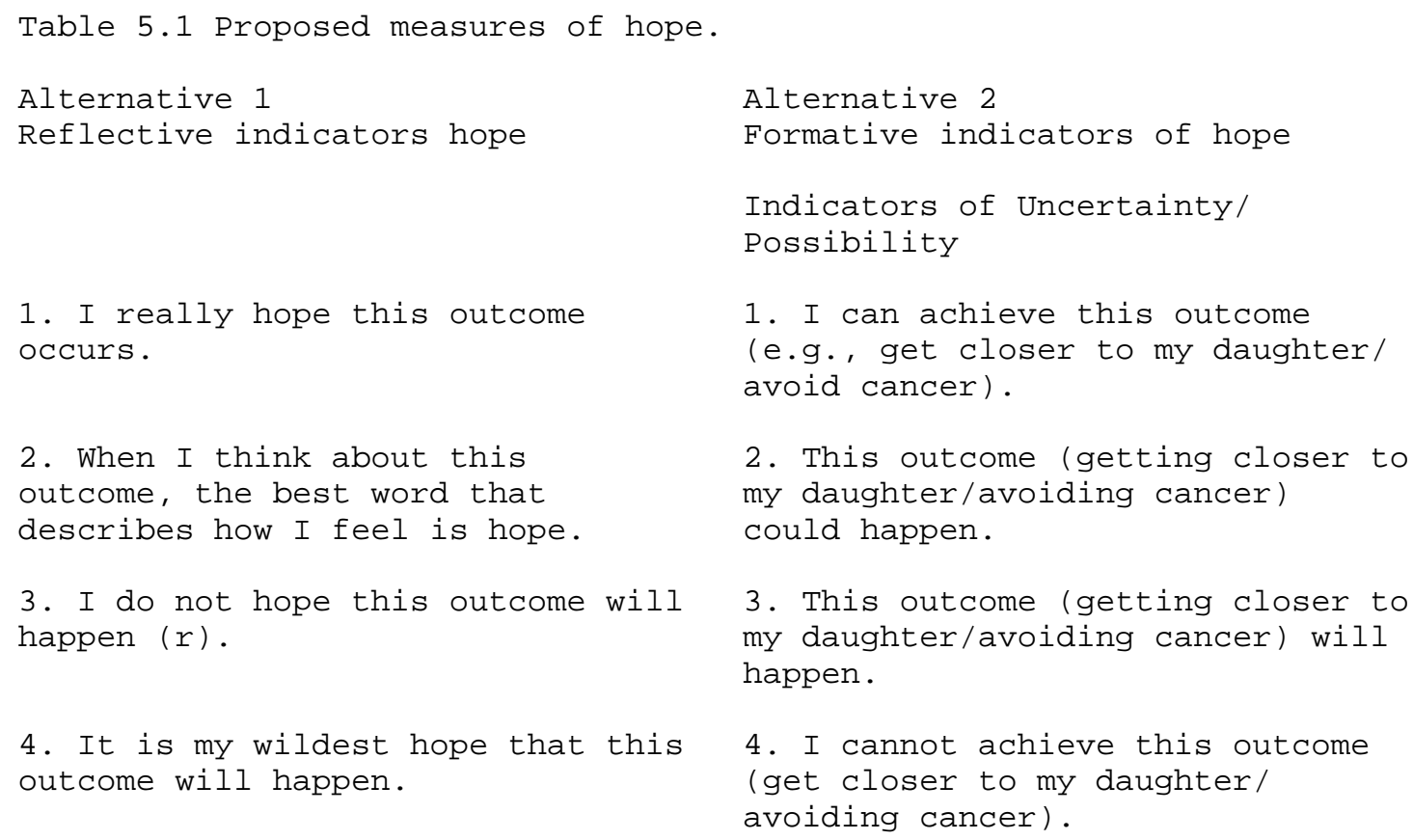


Example for a positive outcome that will happen:

1. I really hope I can get closer to my daughter.

2. When I think about being closer to my daughter, the best word to describe how I feel is hope.

3. I do not hope I get closer to my daughter (r).

4. It is my wildest hope that I will get closer to my daughter.

Example for a negative outcome that can be avoided:

1. I really hope I can avoid cancer.

2. When I think about avoiding cancer, the best word to describe how I feel is hope.

3. I do not hope I avoid cancer (r).

4. It is my wildest hope that I can avoid to get cancer.

(1 = strongly disagree;

7 = strongly agree)
5. This outcome could never happen (get closer to my daughter/avoid cancer).

6. This outcome (getting closer to my daughter/avoiding cancer) will not happen.

I am ( 1 = certain; 7 = uncertain $)$ about whether this statement is true.

Indicators of Yearning:

I. Indicators of Desire

1a. I really want this outcome to happen (get closer to my daughter/avoid cancer).

1b. It would give me a lot of pleasure to have this outcome happen (get closer to my daughter/avoid cancer).

1c. I have no desire to achieve

this outcome (get closer to my daughter/avoid cancer) (r).

II. Indicators of Importance

2a. Achieving this outcome (getting closer to my daughter/ avoiding cancer) is very important to me.

2b. This outcome (getting closer to my daughter/avoiding cancer) is very relevant to me.

$2 \mathrm{c}$. Whether or not this outcome (getting closer to my daughter/ avoiding cancer) happens has little significance to me.

2d. Achieving this outcome (getting closer to my daughter/ avoiding cancer) is very meaningful to me.

III. Indicators of Deficiency

3a. I feel I need more of this outcome (to get closer to my daughter, to do more to avoid cancer).

3b. It seems like so many other people have achieved this outcome (gotten closer to their daughter, avoided cancer) than me.

3c. I do not feel I have enough of this outcome right now (closeness to my daughter, resources to ward off cancer). 
3d. I would hate to have more of this outcome (closeness to my daughter, resources to ward off cancer) than I have right now ( $r$ ).

Hope = a positive emotion that varies as a function of the degree of yearning for a (goal congruent, future-oriented) outcome appraised as uncertain, yet possible.

Goal Congruent Outcomes:

* Positive outcomes (e.g., losing weight, having nice furniture, getting a relaxing vacation, being closer to my daughter, finding a life partner, winning a championship) will occur.

* Negative outcomes (e.g., getting cancer, traffic, gaining weight, getting osteoporosis, getting wrinkles, paying for auto accidents, having a house fire) will be avoided. 


\section{Discussion}

\subsection{Contributions}

Hope is an emotion of vital relevance for consumers. Its pervasiveness in our lives, in the arts, in religion, and in the marketplace attests to its import in human existence. Paradoxically, the study of this emotion remains scarce across diverse disciplines and is non-existent in consumer behavior. While researchers in other disciplines have dealt with the concept and provided definitions, a clear and definitive characterization of this emotion has proved elusive. In the marketing literature, while researchers have analyzed concepts related to hope--desire, and involvement, for instance--these constructs are distinct from hope. The purpose of the present paper has been to suggest its potential relevance to consumer behavior.

A primary contribution of the present paper is offering a new and comprehensive definition of hope. Our view of hope as a positive emotion that varies as a function of the degree of yearning for a (goal-congruent, future-oriented) outcome appraised as uncertain, yet possible goes beyond simply aggregating the existing knowledge on hope. It amends the lack of clarity that this concept has in definitions in the extant literature and disentangles hope from related but conceptually distinct concepts, including hopefulness.

A second contribution is the articulation of a typology of consumer hope that recognizes that consumers can experience hope in a number of life domains and can have hope for products/services, consumption outcomes, and themselves, all linked in a mutually interactive and reinforcing manner.

A third contribution is consideration of the effects of hope on significant consumer behavior, specifically self-deception and risk-taking behavior. Outcomes derived from hope-induced biased information processing and risk taking can result in consequences that range from the harmlessly comic to the tragic. Importantly, these outcomes cannot be explained by known consumer behavior constructs like involvement.

Fourth, we examined the potential effects of hope on outcomes previously studied by consumer researchers--product satisfaction, life satisfaction, and materialism. Our propositions related to product satisfaction suggest that marketers may always benefit from enhancing the hope consumers feel since fulfilling hope leads to feelings of joy and delight, while failure to fulfill hope is linked with only mild disappointment, particularly when novel products or services that might fulfill hope are identified. However, this same outcome may contribute to consumer unhappiness and foster over-consumption. Our analysis suggests that the commoditization of hope fostered by marketers is one of the factors leading to the self-defeating cycle of consumption in which certain individuals engage. Our study thus calls for needs to examine normative implications of creating or enhancing consumers' hope.

Fifth, we considered the extent to which consumers use the marketplace as a source of hope and tactics used by marketers to generate hope. The novel propositions advanced along with these issues strongly hint at the copious stream of research that opens for marketing scholars.

The introduction of a new and comprehensive definition of hope, the advancement of novel avenues of research, and testable propositions carry with them the necessity of having an adequate measuring tool for hope. A sixth contribution of the paper is development of a preliminary hope measure derived from the proposed definition. We have listed the shortcomings of the existing measures. While developing a complete and definitive measure is far beyond the scope of this conceptual paper, we trust that the present effort will jumpstart works aimed at elaborating and refining an appropriate measure of hope that will make possible the much-needed research in this area.

\subsection{Extensions and Future Research}


In addition to the issues raised above, a number of additional research questions can be raised about hope. Answers to these questions are unclear given the lack of research on the topic.

\subsubsection{The Dynamic Nature of Hope}

First, one wonders about potential dynamic issues in the nature and intensity of hope over time. Do consumers specify a time period in which the hoped for outcome is achieved? Does lack of a specify time frame insulate the consumer from potential disappointment if the goal congruent outcome is not achieved within the specified time frame? Consider also how the time frame between the present and the potential achievement of a goal may change the intensity of hope. Does a consumer who hopes that her new living room furniture will transform her house experience more hope for this transformation as the time of its delivery gets closer?

\subsubsection{Considering Hope and Hopefulness}

Second, while hope and hopefulness are conceptually distinct, one wonders to what extent they are positively correlated in a natural environment. Are consumers who hope to attain a good relationship, financial success, a beautiful home, and have a sports team win a championship predisposed to being hopeful that these outcomes will arise? It is also possible that hopefulness may mediate the effects of hope. For example, hope may stimulate self-deception, risk-taking tendencies and materialism because the act of yearning stimulates hopefulness of good outcomes. On the other hand, perhaps being hopeful about a goal congruent outcome encourages imagined scenarios about how wonderful this outcome would make one's life, stimulating yearning and hence hope.

One can also ask how varying levels of hopefulness may affect consumer behavior when hope is intense. Consider the fist situation in which a consumer has intense hope for a goal congruent outcome and is hopeful that it can occur. Pommer et al. (1985) found that patients who were hopeful about an outcome for which they had intense levels of hope (e.g., surviving a kidney transplant operation) were more likely to recover from operations and to be more willing to try a future operation in the event that this one failed. Motivation to pursue the goal congruent selves, outcomes, and products shown in Table 2.1 may be greatest when consumers not only hope that the outcome can be achieved but are hopeful that it will be achieved.

Consumers engaged in such self-regulation activities as dieting, refraining from smoking, staying drug free, saving money (budgeting), and exercising are more likely to be successful when they feel intense hope about achieving these outcomes (induced by internally or externally stimulated goals) and are given tools and information that make them hopeful that these outcomes can be achieved. Beyond a self-regulation context, consumers may be more motivated to get makeovers, have plastic surgery, enter an athletic competition, participate in fundraising for a worthy cause, pursue relationships, patch them up, and end them when hope is intense and they are hopeful that their actions will yield the results for which they yearn.

Finally, consider a situation in which the consumer has intense hope for a goal congruent outcome (e.g., beauty, health, good relationships, material success), but lacks hopefulness that it could come to fruition. Feelings of depression, alienation, or futility will likely result. The most probable emotional victims of marketplace activities are those who have come to intensely hope for wealth, material success, beauty through marketing communications that heighten yearning, yet whose capacities for achieving them is perceived as quite limited.

\subsubsection{How Does Hope Relate to Compensatory Consumption?}

A set of questions can also be addressed about hope and compensatory consumption. If consumers hope for selves, outcomes, and products across a number of domains, to what extent does the pursuit of hope in one or more domains shown in Table 2.1 compensate for deficiencies in another? Will a consumer with extreme deficiency in one life domain sublimate this deficiency by overcompensating in the pursuit of hope in another? Consider a consumer whose limited education and occupational choices renders it impossible for 
him to achieve hopes of economic success through employment. Will such a consumer downplay the necessity of hopes in such domains and become hyper-vigilant in, say, body building? Alternatively, to what extent can hope in one or more of the levels of hope in Table 2.1 compensate for hope in another level? Can hope for a better car, financial success, or the perfect engagement ring substitute for hope for a happier and more meaningful life? To date, answers to these questions are not clear.

\subsubsection{Are There Trade-offs Between Hopes for Self and Others?}

Goals can be individual or communal as when groups of individual are joined in their vision for a common/shared goal (Snyder et al., 1997). As such, it is possible to think of hope at different levels of analysis. Nunn (1996) writes, 'it is preferable to refer to individual, group, family, communal, corporate, or collective hope" (pg. 229). Averill et al. (1990) also End that participants described hoping for the well-being of another person (i.e., altruistic hopes). Are parents' hopes for their children greater than their hopes for themselves? What happens when individual level hopes are incongruent with societal hopes? Such is the case with materialism, where pursuit of individual hope of Ending satisfaction in the marketplace is at the expense of fulfilling societal hopes like limited pollution, saving the planet's scarce resources, and the like. It is perhaps in this vein that Goodall and Berman's (2000) Reason for Hope focuses on the necessity of individual and collective efforts to ensure a continuation of our life on earth.

\subsection{Conclusion}

The aims of this paper are ambitious: introducing and conceptualizing a construct that has proved elusive even in a broader multidisciplinary literature base. The evidence here suggests the importance and relevance of this topic to consumer research. It makes clear that the concept of hope is rich in its potential to provide insight into consumer behavior. While this has not been a comprehensive identification of the relevance of hope to our discipline, the issues identified herein will hopefully serve as the basis for future empirical work on the concept in consumer behavior.

\section{References}

Agrawal, N. and D. Maheswaran (2005), 'Motivated reasoning in outcome-bias effects'. Journal of Consumer Research 31(March), 798-805.

Alcock, J. (1995), 'The belief engine'. Skeptical Inquirer 19(3), 14-18.

Arnold, M. B. (1960), Emotion and Personality, Vol. 1: Psychological Aspects. New York: Columbia University Press.

Austin, J. T. and J. B. Vancouver (1996), 'Goal constructs in psychology: Structure, process, and content'. Psychological Bulletin 120(3), 338-375.

Averill, J. R. (1991), 'Intellectual emotions'. In: C. D. Spielberger, I. G. Sarason, Z. Kulcsar, and G. L. Van Heck (eds.): Stress and Emotion: Anxiety, Anger and Curiosity, Vol. 14. Washington: Taylor \& Francis, pp. 316.

Averill, J. R., G. Catlin, and K. C. Kyum (1990), The Rules of Hope. New York: Springer-Verlag.

Bagozzi, R. P. (1982), 'The role of measurement in theory construction and hypothesis testing: Toward a holistic model'. In: C. Fornell (ed.): A Second Generation of Multivariate Analysis, Vol. 1. New York: Praeger, pp. 5-23.

Bagozzi, R. P. (1994), 'Structural equation models in marketing research: Basic principles'. In: R. P. Bagozzi (ed.): Principles of Marketing Research. Oxford: Blackwell, pp. 317-385. 
Bagozzi, R. P., H. Baumgartner, R. Pieters, and M. Zeelenberg (2000), 'The role of emotions in goal-directed behavior'. In: S. Ratneshwar, D. G. Mick, and C. Huffman (eds.): The Why of Consumption: Contemporary Perspectives on Consumer Motives, Goals, and Desires. New York: Routledge, pp. 36-58.

Bagozzi, R. P. and U. Dholakia (1999), 'Goal setting and goal striving in consumer behavior'. Journal of Marketing 63(Special Issue), 1932.

Bagozzi, R. P. and C. Fornell (1982), 'Theory concepts, measurement, and meaning'. In: C. Fornell (ed.): A Second Generation of Multivariate Analysis, Vol. 1. New York: Praeger, pp. 2438.

Bagozzi, R. P., M. Gopinath, and P. Nyer (1999), 'The role of emotions in marketing'. Journal of the Academy of Marketing Science 27(2), 184-206.

Bandura, A. (1997), Self-Efficacy: The Exercise of Control. NY: W. H. Freeman \& Co.

Baudrillard, J. (1983), Simulations (P. Foss, P. Patton, and P. Beitchman, Trans.). NY: Semiotext[e].

Belk, R. W. (1984), 'Three scales to measure constructs related to materialism: Reliability, validity, and relationships to measures of happiness'. In: T. Kinnear (ed.): Advances in Consumer Research, Vol. 11. Provo, UT: Association for Consumer Research, pp. 291297.

Belk, R. W. (1985), 'Materialism: Trait aspects of living in the material world'. Journal of Consumer Research 12(December), 265280. Belk, R. W. (1987), 'A child's christmas in America: Santa claus as deity, consumption as religion'. Journal of American Culture 10(1, Spring), 87-100.

Belk, R. W. (1989), 'Materialism and the modern U.S. Christmas'. In: E. Hirschman (ed.): Interpretive Consumer Research. Provo, UT: Association for Consumer Research, pp. 115135.

Belk, R. W. (1996), 'On aura, illusion, escape, and hope in apocalyptic consumption: The apotheosis of Las Vegas'. In: S. Brown, J. Bell, and D. Carson (eds.): Marketing Apocalypse: Eschatology, Escapology, and the Illusion of the End. London: Routledge, pp. 87-107.

Belk, R. W., G. Ger, and S. Askegaard (1997), 'Consumer desire in three cultures: Results from projective research'. In: M. Brucks and D. J. MacInnis (eds.): Advances in Consumer Research, Vol. 24. Provo, UT: Association for Consumer Research, pp. 24-28.

Belk, R. W., G. Ger, and S. Askegaard (2003), 'The fire of desire: A multisited inquiry into consumer passion'. Journal of Consumer Research 30(December), 326-351.

Bloch, E. (1986), The Principle of Hope. Cambridge, MA: MIT Press.

Bollen, K. and R. Lennox (1991), 'Conventional wisdom on measurement: A structural equation perspective'. Psychological Bulletin 110(2), 305314.

Boorstin, D. J. (1992), The Image: A Guide to Pseudo-Events in America. NY: Vintage Books.

Brown, J. F. (1994), Hopes and Shadows: Eastern After Communism. Durham, NC: Duke University Press.

Bruininks, P. and B. F. Malle (2005), 'Distinguishing hope from optimism and related affective states'. Motivation and Emotion 29(December), 327355.

Brumberg, J. J. (1998), The Body Project: An Intimate History of American Girls. New York: Vintage Books. 
Campbell, C. (1987), The Romantic Ethic and the Spirit of Modern Consumerism. London: Blackwell.

Cantor, N., J. K. Norem, P. Niedenthal, C. Langston, and A. Brower (1987), 'Life tasks, self-concept ideals, and cognitive strategies in a life transition'. Journal of Personality and Social Psychology 53(6), 11781191.

Cantril, A. H. and C. W. Roll, Jr. (1971), Hopes and Fears of the American People. New York: Universe Books.

Carver, C. S., S. L. Reynolds, and M. F. Scheier (1994), 'The possible selves of optimists and pessimists'. Journal of Research in Personality 28(2, June), 133141.

Celsi, R. L., R. L. Rose, and T. W. Leigh (1993), 'An exploration of high-risk leisure consumption through skydiving'. Journal of Consumer Research 20(June), 123.

Chaffray, C. M. and S. L. Schneider (2000), 'Why do they do it?: Affective motivators in adolescents' decisions to participate in risky behaviours'. Cognition and Emotion: Special Issue on Emotion, Cognition and Decision Making 14(July), 543-576.

Chaiken, S., A. Liberman, and A. H. Eagly (1989), 'Heuristic and systematic processing within and beyond the persuasion context'. In: J. S. Uleman and J. A. Bargh (eds.): Unintended Thought. New York: Guilford.

Churchill Jr., G. A. (1979), 'A paradigm for developing better measures of marketing constructs'. Journal of Marketing Research 16(1), 6473.

Clotfelter, C. T. and P. J. Cook (1989), Selling Hope: State Lotteries in America. Cambridge: Harvard University Press.

Cohen, J. (1958), Humanistic Psychology. Allen and Unwin.

Cross, S. and H. Markus (1991), 'Possible selves across the life span'. Human Development 34, $230-255$.

Csikszentmihalyi, M. (2000), 'Costs and benefits of consuming'. Journal of Consumer Research 27(September), 267272.

Cushman, P. (1990), 'Why the self is empty'. American Psychologist 45(May), 599511.

Davidson, K. (1998), 'Marketing this 'hope' sells our profession short'. Marketing News 20(July), 6.

de Mello, G. E. and D. J. MacInnis (2005), 'Why and how consumers hope: Motivated reasoning and the marketplace'. In: S. Ratneshwar and D. G. Mick (eds.): Inside Consumption: Consumer Motives, Goals, and Desires. London/New York: Routledge, pp. 4456.

Diamantopoulos, A. and H. M. Winklhofer (2001), 'Index construction with formative indicators: An alterative to scale development'. Journal of Marketing Research 39(May), 269277.

Eagly, A. H. and S. Chaiken (1993), The Psychology of Attitudes. Orlando, FL: Harcourt Brace Jovanovich College Publishers.

Eagly, A. H., W. Wood, and S. Chaiken (1978), 'Causal inferences about communicators and their effects on opinion change'. Journal of Personality and Social Psychology 36(April), 424-435.

Fisk, R. P. and C. E. Young (1985), 'Disconfirmation of equity expectations: effects on consumer satisfaction with services'. In: E. Hirschman and M. Holbrook (eds.): Advances in Consumer Research. Provo, UT: 
Association for Consumer Research, pp. 340345.

Fitzgerald, R. (1979), 'The genesis of hope: The case of alcoholics anonymous'. In: R. Fitzgerald (ed.): The Sources of Hope. Australia: Pergamon Press, pp. 67-87.

Folkes, V. S. (1984), 'Consumer reactions to product failure an attribution approach'. Journal of Consumer Research 10(March), 398-409.

Folkes, V. S. (1988), 'Recent attribution research in consumer behavior: A review and new directions'. Journal of Consumer Research 14(March), 548-565.

Folkman, C. (1999), 'In hope of an enduring gift: The intergenerational transfer of cherished possessions: A special case of gift giving'. In: S. Hoch and R. Meyer (eds.): Advances in Consumer Research, Vol. 26. Provo, UT: Association for Consumer Research, pp. 125-132.

Forgas, J. P., G. H. Bower, and S. Krantz (1984), 'The influence of mood on perceptions of social interactions'. Journal of Experimental Social Psychology 20, 497-513.

Frijda, N. H. (2000), 'The psychologists' point of view'. In: M. Lewis and J. M. Haviland-Jove (eds.): Handbook of Emotions. New York: The Guilford Press, second edition, pp. 59-74.

Frijda, N. H., P. Kuipers, and E. ter Schure (1989), 'Relations among emotion, appraisal, and emotional action readiness'. Journal of Personality and Social Psychology 57(2), 212-228.

Gelwick, R. (1979), 'Post-critical beliefs'. In: R. Fitzgerald (ed.): The Sources of Hope. Sydney: Pergamon Press.

Gillham, J. E., A. J. Shatte, K. J. Reivich, and M. E. Seligman (2001), 'Optimism, pessimism, and explanatory style'. In: C. E. Chang (ed.): Optimism and Pessimism: Implications for Theory, Research, and Practice. Washington DC: American Psychological Assocation.

Gilovich, T. (1983), 'Biased evaluation and persistence in gambling'. Journal of Personality and Social Psychology 44, 11101126.

Gilovich, T. (1991), How We Know What Isn't So: The Fallibility of Human Reason in Everyday Life. New York, NY: The Free Press.

Goodall, J. and P. L. Berman's (2000), 'Reason for Hope: A Spiritual Journal'. New York, NY: Warner Books.

Gutman, J. (1982), 'A means-end chain model based on consumer categorization processes'. Journal of Marketing 46(Spring), 60-72.

Haase, J. E., T. Britt, D. D. Conward, N. L. Leidy, and P. E. Penn (1992), 'Simultaneous concept analysis of spiritual perspective, hope, acceptance and self-transcendence'. IMAGE: Journal of Nursing Scholarship 24(Summer), 141-147.

Hamilton, G. G. (1978), 'The structural sources of adventurism: The case of the california gold rush'. American Journal of Sociology 83(May), 14661490.

Hardie, B., E. Johnson, and P. Fader (1993), 'Modeling loss aversion and reference dependence effects on brand choice'. Marketing Science 12(Fall), 378-394. 
Heilmann, M. (1997), 'Self-deceived about self-deception: An evolutionary analysis'. Behavioral and Brain Sciences 20(1), 116117.

Herth, K. (1992), 'Abbreviated instrument to measure hope: Development and psychometric evaluation'. Journal of Advanced Nursing 17, 12511259.

Higgins, E. T. (1987), 'Self-discrepancy: A theory relating self and affect'. Psychological Review 94(3), 319340.

Higgins, E. T. (1997), 'Beyond pleasure and pain'. American Psychologist 52(12), 12801300.

Higgins, E. T., R. N. Bond, R. Klein, and T. Strauman (1986), 'Self-discrepancies and emotional vulnerability: How magnitude, accessibility, and type of discrepancy influence affect'. Journal of Personality and Social Psychology 51(1), 515.

Hirschman, E. C. (1988), 'The ideology of consumption: A structural-syntactical analysis of 'Dallas' and 'Dynasty". Journal of Consumer Research 15(December), 344359.

Huffman, C., S. Ratneshwar, and D. G. Mick (2000), 'Consumer goal structures and goal-determination processes: An integrative framework'. In: S. Ratneshwar, D. G. Mick, and C. Huffman (eds.): The Why of Consumption: Contemporary Perspectives on Consumer Motives, Goals, and Desires. NY: Routledge, pp. 935.

Isen, A. (1987), 'Positive affect, cognitive processes and social behavior'. In: L. Berkowitz (ed.): Advances in Experimental Social Psychology, Vol. 20. NY: Academic Press, pp. 203-253.

Jain, S. P. and D. Maheswaran (2000), 'Motivated reasoning: A depth-of processing perspective'. Journal of Consumer Research 26(4), 358-371.

Kahn, B. E. and A. M. Isen (1993), 'The influence of positive affect on variety seeking among safe, enjoyable products'. Journal of Consumer Research 20(2), 257-270.

Kast, V. (1991), Joy, Inspiration, and Hope. College Station, TX: Texas A \& M Press.

Keng, K. A., K. Jung, T. S. Jiuan, and J. Wirtz (2000), 'The influence of materialistic inclination on values, life satisfaction, and aspirations: An empirical analysis'. Social Indicators Research 49, 317333.

Korner, I. N. (1970), 'Hope as a method of coping'. Journal of Consulting and Clinical Psychology 34(2), 134-139.

Kunda, Z. (1987), 'Motivated inference: Self-serving generation and evaluation of causal theories'. Journal of Personality and Social Psychology 53, 636347.

Kunda, Z. (1990), 'The case for motivated reasoning'. Psychological Bulletin 108(3), 480-498.

Langenderfer, J. and T. A. Shimp (2001), 'Consumer vulnerability to scams, swindles, and fraud: A new theory of visceral influences on persuasion'. Psychology and Marketing 18(7), 763-783.

Lazarus, R. S. (1991), Emotion and Adaptation. New York: Oxford University Press.

Lazarus, R. S. (1999a), 'Hope: An emotion and a vital coping resource against despair'. Social Research 66(2), 653378. 
Lazarus, R. S. (1999b), Stress and Emotion: A New Synthesis. NY: Springer.

Lester, G. W. (2000), 'Why bad beliefs don't die'. Skeptical Inquirer 24(6), 40-43.

MacInnis, D. J. and G. E. de Mello (2005), 'The concept of hope and its relevance to product evaluation and choice'. Journal of Marketing 69(January), 114.

MacInnis, D. J., G. E. de Mello, and V. M. Patrick (2004), 'Consumer hopefulness: Construct, relevance to internet marketing, antecedents, and consequences'. International Journal of Internet Marketing and Advertising 1(2), 174195.

MacInnis, D. J. and L. Price (1987), 'The role of imagery in information processing: Review and extensions'. Journal of Consumer Research 13(March), 473-492.

Markus, H. and P. Nurius (1986), 'Possible selves'. American Psychologist 41(September), 954-969.

Markus, H. and A. Ruvolo (1989), 'Possible selves: Personalized representations of goals'. In: L. A. Pervin (ed.): Goal Concepts in Personality and Social Psychology. Hillsdale NJ: Lawrence Erlbaum, pp. 211-241.

Markus, H. and E. Wurf (1987), 'The dynamic self-concept: A social psychological perspective'. Annual Review of Psychology 38, 299-337.

McAlexander, J. H. and J. W. Schouten (1989), 'Hair style changes as transition markers'. Sociology and Social Research 74(October), 5832.

McCracken, G. (1990), Culture and Consumption: New Approaches to the Symbolic Character of Consumer Goods and Activities. Bloomington, IN: Indiana University Press.

McGuire, W. J. and A. Padawer-Singer (1976), 'Trait salience in the spontaneous self-concept'. Journal of Personality and Social Psychology 33, 743-754.

Mele, A. (1997), 'Real self-deception'. Behavioral and Brain Sciences 20(1), 91-136.

Mergenhagen, P. (1995), Targeting Transitions: Marketing to Consumers During Life Changes. Ithaca, NY: American Demographics Books.

Miller, J. F. and M. J. Powers (1988), 'Development of an instrument to measure hope'. Nursing Research $37(1), 610$.

Moltmann, J. (1980), Experiences of God (M. Kohl, Trans). Philadelphia: Fortress Press.

Nowotny, J. (1979), 'Despair and the Object of Hope'. In: R. Fitzgerald (ed.): The Sources of Hope. Australia: Pergamon Press.

Nunn, K. P. (1996), 'Personal hopefulness: A conceptual review of the relevance of the perceived future to psychiatry'. British Journal of Medical Psychology 69(Suppl. 3, September), 227245.

Nunn, K. P., T. J. Lewin, J. M. Walton, and V. J. Carr (1996), 'The construction and characteristics of an instrument to measure personal hopefulness'. Psychological Medicine 26, 531-545.

Obayuwana, A., J. L. Collins, A. L. Carter, M. S. Rao, C. C. Mathura, and S. B. Wilson (1982), 'Hope index scale: An instrument for the objective assessment of hope'. Journal of the National Medical Association 74(8), 761-765. 
Oettingen, G., H. Pak, and K. Schnetter (2001), 'Self-regulation of goal setting: Turning free fantasies about the future into binding goals'. Journal of Personality and Social Psychology 80(5), 736753.

O'Guinn, T. C. and R. W. Belk (1989), 'Heaven on earth: Consumption at heritage village, USA'. Journal of Consumer Research 16(September), 227-238.

Oliver, R. L. and W. DeSarbo (1988), 'Response determinants in satisfaction judgments'. Journal of Consumer Research 14(March), 495507.

Oliver, R. L. and R. S. Winer (1987), 'A framework for the formation and structure of consumer expectations: Review and propositions'. Journal of Economic Psychology 8, 469-499.

Park, C. W. and B. Mittal (1985), 'A theory of involvement in consumer behavior: Problems and issues'. In: J. N. Sheth (ed.): Research in Consumer Behavior. Greenwich, CT: JAI Press, pp. 201231.

Peiss, K. (1998), Hope in a Jar: The Making of America's Beauty Culture. New York: Metropolitan Books.

Petty, R. E. and J. T. Cacioppo (1986), Communication and Persuasion: Central and Peripheral Routes to Attitude Change. New York: Springer-Verlag.

Pham, M. T. and E. T. Higgins (2005), 'Promotion and prevention in consumer decision-making: The state of the art and theoretical propositions'. In: S. Ratneshwar and D. G. Mick (eds.): Inside Consumption: Consumer Motives, Goals, and Desires. London/New York: Routledge.

Pieper, J. (1994), Hope and History: Five Salzburg Lectures. San Francisco, CA: Ignatius.

Plutchik, R. (1980), Emotion: A Psychoevolutionary Synthesis. New York: Harper \& Row.

Pollay, R. W. (1986), 'The distorted mirror: Reflections on the unintended consequences of advertising'. Journal of Marketing 50(April), 18-36.

Pommer, W., P. Diederichs, M. Hummel, P. Kratzer, and G. Offerman (1985), 'Patients' expectations from renal grafting and transplantation outcome'. Psychotherapy and Psychosomatics 44, 95-102.

Przybyla, D. P., D. Byrne, and K. Kelley (1983), 'The role of imagery in sexual behavior'. In: A. A. Sheikh (ed.): Imagery: Current Theory, Research and Application. NY: John Wiley and Sons, pp. 436-467.

Reynolds, T. G. and J. Gutman (1988), 'Laddering theory, method, analysis and interpretation'. Journal of Advertising Research 28(March), 1131.

Richins, M. L. (1991), 'Social comparison and the idealized images of advertising'. Journal of Consumer Research 18(June), 71-83.

Richins, M. L. (1994), 'Special possessions and the expression of material values'. Journal of Consumer Research 21(December), 522-533.

Richins, M. L. (1995), 'Social comparison, advertising, and consumer discontent'. American Behavioral Scientist 38(February), 593507.

Richins, M. L. (1997), 'Measuring emotions in the consumption experience'. Journal of Consumer Research 24(September), 127146.

Richins, M. L. and S. Dawson (1992), 'A consumer values orientation for materialism and its measurement: 
Scale development and validation'. Journal of Consumer Research 19(December), 303316.

Richins, M. L. and F. Rudmin (1994), 'Materialism and economic psychology'. Journal of Economic Psychology 15, 217-231.

Rose, R. L., W. O. Bearden, and J. E. Teel (1992), 'An attributional analysis of resistance to group pressure regarding illicit drug and alcohol consumption'. Journal of Consumer Research 19(June), 113.

Roseman, I. (1991), 'Appraisal determinants of discrete emotions'. Cognition and Emotion 5(3, May), 161200 .

Roseman, I. J. (1984), 'Cognitive determinants of emotion: A structural theory'. Review of Personality and Social Psychology 5, 1136.

Roseman, I. J., M. S. Spindel, and P. E. Jose (1990), 'Appraisals of emotion-eliciting events: Testing a theory of discrete emotions'. Journal of Personality and Social Psychology 59(5), 899-915.

Roseman, I. J., C. Wiest, and T. S. Schwartz (1994), 'Phenomenology, behaviors, and goals differentiate discrete emotions'. Journal of Personality and Social Psychology 67(2, August), 206-221.

Ross, L., D. Green, and P. House (1977), 'The false consensus effect: An egocentric bias in social perception and attribution processes'. Journal of Experimental Social Psychology 12, 279288.

Russell, J. A. (1980), 'A circumplex model of affect'. Journal of Personality and Social Psychology 39(6), 1161-1178.

Rycroft, C. (1979), 'Steps to an ecology of hope'. In: R. Fitzgerald (ed.): The Sources of Hope. Australia: Pergamon Press, pp. 36-53.

Schaller, M. and R. B. Cialdini (1990), 'Happiness, sadness, and helping: A motivational integration'. In: E. T. Higgins and R. M. Sorrentino (eds.): Handbook of Motivation and Cognition: Foundations of Social Behavior, Vol. 2. New York, NY: The Guilford Press.

Scheier, M. and C. S. Carver (1985), 'Optimism, coping and health: Assessment and implications of generalized outcome expectancies'. Health Psychology 4, 219247.

Scheier, M. and C. S. Carver (1987), 'Dispositional optimism and physical well-being: The influence of generalized outcome expectancies'. Health Psychology 4, 219247.

Schouten, J. W. (1991), 'Selves in transition: Symbolic consumption in personal rites of passage and identity reconstruction'. Journal of Consumer Research 17(March), 412-425.

Schultze, Q. J. (1991), Televangelism and American Culture: The Business of Popular Religion. Grand Rapids, MI: Baker Book House.

Schwartz, N. (1990), 'Feelings as information: Informational and motivational functions of affective states'. In: E. T. Higgins and R. M.

Sorrentino (eds.): Handbook of Motivation and Cognition: Foundations of Social Behavior, Vol. 2. New York, NY: The Guilford Press.

Seligman, M. E. P. (1991), Learned Optimism. New York: Knopf. Shaver, P., J. Schwartz, D. Kirson, and C. O'Connor (1987), 'Emotion knowledge: Further exploration of a prototype approach'. Journal of Personality 
and Social Psychology 52(6), 10611086.

Shea, L. S. (1981), Stone Soup: A Psychology of Hope. Doctoral Dissertation, Union Institute and University.

Shimanoff, S. B. (1984), 'Commonly named emotions in everyday conversations'. Perceptual and Motor Skills 58(2, April), 514.

Showers, C. (1992), 'The motivational and emotional consequences of considering positive or negative possibilities for an upcoming event'. Journal of Personality and Social Psychology 63, 474-484.

Sirgy, M. J., D. Lee, K. Rustan, H. L. Meadow, D. Rahtz, M. Cicic, G. X. Jin, D. Yarsuvat, D. L. Blenkhort, and N. Wright (1998), 'Does television viewership play a role in the perception of quality of life?'. Journal of Advertising 27(Spring), 125-142.

Smith, C. A. and P. C. Ellsworth (1985), 'Patterns of cognitive appraisal in emotion'. Journal of Personality and Social Psychology 48(4), 813-838.

Smith, C. A., K. N. Haynes, R. S. Lazarus, and L. K. Pope (1993), 'In search of the 'Hot" cognitions: Attributions, appraisals and their relation to emotion'. Journal of Personality and Social Psychology 65(5, November), 916-929.

Snyder, C. R., J. Cheavens, and S. C. Sympson (1997), 'Hope: An individual motive for social commerce'. Group Dynamics: Theory, Research and practice 1(2, June), 107118.

Snyder, C. R., C. Harris, J. R. Anderson, S. A. Holleran, L. M. Irving, S. T. Sigmon, L. Yoshinobu, J. Gibb, C. Langelle, and P. Harney (1991), 'The will and the ways: Development and validation of an individual differences measure of hope'. Journal of Personality and Social Psychology 60(4), 570-585.

Snyder, C. R., S. C. Sympson, F. C. Ybasco, T. F. Borders, M. A. Babyak, and R. L. Higgins (1996), 'Development and validation of the state hope scale'. Journal of Personality and Social Psychology 70(2), 321-335.

Solomon, M. R. (1983), 'The role of products as social stimuli: A symbolic interactionism perspecitve'. Journal of Consumer Research 10(December), 319329.

Solomon, R. C. (2000), 'The philosophy of emotions'. In: M. Lewis and J. M. Haviland-Jones (eds.): Handbook of Emotions. NY: Guilford Press, pp. 315.

Spinoza, B. (1960), 'The Origin and Nature of the Emotions'. In: Spinoza's Ethics. Dent: Everyman.

Spreng, R. A., S. B. MacKenzie, and R. W. Olshavsky (1996), 'A reexamination of the determinants of consumer satisfaction'. Journal of Marketing 60(July), 15-32.

Staats, S. (1989), 'Hope: A comparison of two self-report measures for adults'. Journal of Personality Assessment 53(2), 366375.

Stotland, E. (1969), The Psychology of Hope. San Francisco: Josey Bass. Szymanski, D. M. and D. H. Henard (2001), 'Customer satisfaction: A meta-analysis of the empirical evidence'. Journal of the Academy of Marketing Science 29(Winter), 1635.

Taylor, S. E., M. Kemeny, G. M. Reed, J. E. Bower, and T. L. Gruenwald (2000), 'Psychological resources, positive illusions and health'. American Psychologist 55(1), 99-109. 
Thomaselli, R. (2001), 'Slam dunk sans superstar'. Advertising Age (6, August), p. 8.

Tiger, L. (1979), Optimism, The Biology of Hope. New York: Simon and Schuster.

Tversky, A. and D. Kahneman (1981), 'The framing of decisions and the psychology of choice'. Science 211(January), 453-458.

van Dolen, W., J. Lemmink, J. Mattsson, and I. Rhoen (2001), 'Affective consumer responses in service encounters: The emotional content in narratives of critical incidents'. Journal of Economic Psychology 22, 359376.

Veroff, J., D. Reuman, and S. Feld (1984), 'Motives of american men and women across the adult life span'. Developmental Psychology 20(November), 11421158.

Watson, D. and A. Tellegen (1985), 'Toward a consensual structure of mood'. Psychological Bulletin 98(September), 219-235.

Westbrook, R. A. and R. L. Oliver (1991), 'The dimensionality of consumption emotion patterns and consumer satisfaction'. Journal of Consumer Research 18(June), 84-91.

Wicklund, R. A. and P. M. Gollwitzer (1982), Symbolic Self-Completion. Hillsdale, NJ: Erlbaum.

Williams, S. and S. Narendran (1999), 'Determinants of managerial risk: Exploring personality and cultural influences'. Journal of Social Psychology 139(1), 102-125.

Woodman, M. (1982), Addiction to Perfection: The Still Unravished Bride. Toronto, Canada: Inner City Books.

Yi, Y. (1990), 'A critical review of consumer satisfaction'. In: V. A.

Zeithaml (ed.): Review of Marketing, Vol. 4. Chicago, IL: American Marketing Association, pp. 68123.

Deborah J. MacInnis (1) and Hae Eun Chun (2)

(1) Marshall School of Business, Marketing Department, University of Southern California, Los Angeles, CA 90089-1443, USA, macinnis@.usc.edu

(2) Marshall School of Business, Marketing Department, University of Southern California, Los Angeles, CA 90089-1443, USA, haechun@usc.edu 